\title{
Optimal Human Resources Allocation in Counter-Terrorism (CT) Operation: A Mathematical Deterministic Model
}

\author{
IJ Udoh* and Navy Capt. MO Oladejo, (Rtd) ${ }^{* *}$
}

Department of Mathematics

Nigerian Defence Academy

PMB 2109, Kaduna, Nigeria

\begin{abstract}
The quest to find a long-term solution to the world's insecurity problems and perhaps, terrorism in particular, has climaxed since the bombing of the World Trade Centre, the USA in September 11th, 2001 by the Al-Qaeda terrorist group. In the last decades, a number of research scholars have developed methodologies from system sciences that attempt to describe and model the behavior of a terrorist group. But their findings tend to converged on a rather intimidating and mind-bugging conclusion. Hence the US Secretary of Defense - Donald Rumsfeld once declared "today we lack relevant metrics to know if we are winning or losing the global war on terror". The present study seeks to construct an analytical model of terrorism to study the possible strategies for allocating given counter-terrorism (CT) resource toward a long-term solution of a given terrorist group. The construct is a simple deterministic model of a terrorist evolutional dynamics, represented by a set of coupled differential equations whose variables are parameters of the internal and external dynamics of the organization. Analytical and numerical simulation techniques are used to study the solution paths of the system of differential equations obtained. By examining the evolutional dynamics of the terrorist operatives under five interdiction strategies, the result shows that, since the evolutional dynamics of most terrorist organization is driven by recruitment process, then any strategy that is capable of maintaining a constant high rate of interdiction of the footsoldiers and the leaders simultaneously, would eventually guarantee a maximum decline in the overall strength of the organization, and as well as engenders a maximum decline in even in the recruiter's pool. Such a strategy has the synergy to weaken the overall terrorists' strength and drive the organization to extinction in the long runs; thus, yielding a comparatively more effective and efficient CT measure than otherwise. For our modeled organization, the interdiction strategy targeted simultaneously at the leaders and foot-soldiers classes, though comparatively cost effective than otherwise and evolved a highly vulnerable strength, yet the propensity to drive the organization to long term inactivity is comparatively low, given the positive exponential growth curves of its strength. The study agreed "that through terror war of attrition may be problematic and costintensive, however, increasing interdiction accuracy is the best-case scenario for ideal CT measures”. Thus, to guarantee interdiction accuracy, sufficient and credible intelligence for smart-targeting of insurgent locations is a panacea. Given the veracity of our model, it is possible to evaluate the efficacy of the various CT policies of the government and hence measure the degree of success or failure of a given CT measure.

Key Words: Terrorism, deterministic model, terrorist operatives, evolutional dynamics, terrorist organization.
\end{abstract}

\subsection{INTRODUCTION}

Insecurity and indeed, terrorism in particular have over the recent decades became the world most ravaging threats to global peace and security, socio-economic and political lives of the vast world population, especially since the bombing of the World Trade Centre in USA in September $11^{\text {th }} 2001$ by the Al-Qaeda terrorist organization. These and other socio-political decadent and ethical decay have been the drivers of the unprecedented explosion of institutions of organized crimes; with its attendant escalation of activities of kidnapping for ransom, hostage-taking, cattle-rustlings, human trafficking, oil bunkering, militancy, politicalassassinations, armed robbery, etc., the world over [13, 27,32]. Globally, the war against terror has proven to be a battle too cumbersome if not impossible to win; as terrorism has gain unprecedented strength and popularity over the past decades, the world over. The cause of this persistent beef-up of the seemingly insurmountable strength and popularity of terrorist organizations has over the recent decades been lopsidedly researched, modeled and analyzed qualitatively, as either a factor of the structural dynamic of the organization or the continuous decay of socio-economic and political development of most world governments. Until recently, however, despite the horrifying loss of life and properties, and as well as vast expenditures on security, comparatively very little quantitative works have been done to study the correlation between the organizational dynamics of the relevant terrorist organizations and their strength. The dearth of such quantitative model of terrorism - mathematical terrorism - is 
not entirely surprising, given the inherent hazardous task of modeling adaptive socio-economic systems like terrorism. Perhaps, it is on this background that the US Secretary of Defense - Donald Rumsfeld once declared: "Today we lack relevant metrics to know if we are winning or losing the global war on terror [19].

The quest to address Rumsfield's challenges and thus, derive a quantitative metrics or a barometric indicator to measure the degree of success or otherwise of the global war against man's growing enemies - the hydra-headed problem of terrorism, informed this renewed interest in the mathematical model of terrorism; to describe and analyze the correlation between a terrorist organizational structure and its strength. The study which hypothesize the modeling of a terrorist organizational strength as a function driven by the internal and external dynamics of its operative's population (leadership, foot-soldiers and recruiters), uses a set of coupled differential equations to describe the structural dynamics of a given terrorist group. The idea of applying mathematical methods to terrorism modeling, though relatively new and interwoven with other disciplines, is typically not common (if found at all) in the applied mathematics academic curriculum. However, certainly students of applied mathematics can still find more benevolent applications of mathematical methods to warfare dynamics at postgraduate level of military operations research $(\mathrm{OR})$ courses.

Mathematicians, new to the area, for example, might be surprised to find an extensive literature on the seemingly trivial problem of defining "terrorism". What makes this taxonomic problem difficult may not be unconnected with the similarity of terrorism to many other anti-social decadent. As a result, reliable data on incidents or groups of terrorist activities was lacking until recently, and a scholarly community was slow to emerge within the social sciences. The hazardous task of developing a mathematical model for a complex and divergent socio-economics system like terrorism isn't surprising also, given the scarcity, validity and reliable training and modeling data; and the fact that terrorists are smart guys. This is even compounded by the complexity of the systems being studied. Secondly, terrorism has ideological, psychological, sociological, and political undertones; among many others factors and so any model can capture only a small cross-section of such a system.

Fortunately, quantitative studies of well-structured elements within this chaotic area, promise to yield new insights into countering terrorism. This study argues that, terrorism though complex and divergent a socio-economics system is an area where mathematical methods can make an impact in a variety of targets and research problems. Judging by the view point of its proponents, "mathematical terrorism" is an area which lies at the clash of disciplines such as operations research (OR), economics and machine learning [21]. Eventually, till date much of the research and policy interest in mathematical terrorism has been as a tool for helping in intelligence gathering - using some sort of statistical algorithm to find a terrorist in a pile of heterogeneous data. This, of-course is a gigantic undertaking and only little real progress can be made to develop such tools, except when the terrorists commit credit card fraud (CCF), in which case terrorism reduces to a known problem where machine learning can play significant role.

\subsection{MATHEMATICAL MODEL OF TERRORISM}

Though applying methods that rely on pure empirical inputs to yield an empirically supported conclusion that is devoid of context and predictive value was challenging and slow, however, a number of mathematicians have developed methodologies from system sciences that attempt to describe and model the behavior of a terrorist organization and their activities. These models attempted to explain the dynamics of terrorist organizations with the expectation that future research will provide predictive value for relevant counter terrorism (CT) stakeholders and decision makers. The earliest quantitative papers specifically on terrorism appeared in the 1980s as a consequence of a wave of international aircraft hijackings of the 1970s [47]. Just as this event led to a resurgence of studies in terrorism, the September 11, 2001 Al-Qaeda attacks on the World trade centre in US, saw an unprecedented renewed interest on why groups resort to terrorism; the specific choice of attack targets; and the relative efficacy of a particular CT measure, and hence the need for a quantitative metrics to measure and evaluate the effectiveness of various CT measures. Among the earliest modeling of a "stock" of terrorists mathematically are "The ecology of terror defense"[36]; "Models for the transmission dynamics of fanatical behaviors" [9]; “What happened to Suicide Bombings in Israel”[34]; and few other dynamical models of terrorism that describe and model the behavior of terrorist organizations $[1,7,10,21,37,49]$.

However, in recent years some of the interesting findings of mathematical terrorism have been in estimating regularities in terrorist attacks and the levels of violence. For example, it has been found that casualties from terrorist events tend to scale as a power law with an exponent of 2.5 , and conflicts across the globe and regions appear to be converging towards a single type of violence as measured by the distribution of its casualties[30,31,45,46]. The significance of this number has been substantiated through various studies based on documented and observed data for terrorists and insurgent organizations. This power-law distribution relationship indicates that terrorist organizations do not operate in a centralized manner but are a result of complex interactions of positive and negative feedback. Although this pattern is a statistical result, complex system models also provided a larger scale of resolution from which to discern the relationship amongst various conflicts. A study on the frequency of severe 
terrorist events also found out that terrorist violence come in waves of period $13 \pm 1$ years[12], though the waves was not proposed on quantitative grounds. When examining the behavior of the system, these studies also suggest that terrorist recruitment process can be degraded by reducing the pool of recruits and level of violence base on variables that are important to the agents in the system.

Till date, few mathematical models of terrorism yielded viable results that can be predictive in nature or provide probabilistic inferences about terrorist organizations. However, most mathematical methods used in terrorism research, focused on developing "data mining tools for identifying terrorist suspects" by applying network analysis, graph theory, control theory, set theory, probability measure, dynamic games theoretic, complex systems methodology, or dynamical systems modeling[17,18,41]. Unlike perhaps fluid dynamics, terrorism as a whole is by far too complex and divergence a phenomenon to be describe by a general mathematical model. At the very least the attempt to formulate a mathematical model helps to raise questions that would not occur to CT experts who tend to be qualitatively-minded. The key advantage of mathematical models is that they lead to compelling consequences which can then be compared with observations. As often as not, the derived consequences may not necessarily agree with the observations but then the direction and magnitude of the departures may indicate the direction of further search.

\subsection{Differential Equation Models of Terrorism:}

The research methodology of modeling global trends and patterns in terrorism with coupled differential equations, owes much to the seminal work of Lewis Fry Richardson in1941. Richardson - a physicist and meteorologist, perhaps best known to social scientists for collecting data on conflicts (or deadly quarrels) and modeling arms races using differential equations, also made early contributions to modeling the frequency severity distributions of wars[45,46]. Richardson showed that the frequency and severity of wars robustly follows a power-law relationship[30,31]; where severity is inversely proportional to frequency. A very significant earliest application of differential equations model to warfare dynamics is credited to Lanchester[38]; who developed the first conventional warfare dynamic model. Lanchester's warfare dynamic equations was a mile stone in dynamical modeling the mathematical technique of describing a complex socio-economic system like terrorism with a set of coupled differential equations has enjoyed a wider application. From this mile stone, the last decades saw various dynamic models of terrorism also hitting the waves of differential equations[1,7,11,21,37,49]. The primary advantages of these models are that the authors provided their estimated parameter values and differential equations. Although much of their data were "notional assumptions", their models were well developed in a progressive fashion. Weaver[52] opined that the accuracy of future models would "depend heavily upon model parameterization and the formulation of effect functions".

To complement the power-law relationships [30,31,45,46], a differential equation model to studied and identifies the robust patterns in the frequency and severity of violent attacks by terrorist organizations in relationship to their organizational size (numerical strength) and experience was also developed[1]. Applying the group-level static and dynamic analyses of terrorist attacks worldwide from 1968 to 2008 and a simulation of its organizational growth, the authors concluded that (a) The production rate of violent events by any terrorist organization depends on its available labor pool (numerical strength), (b) The time between subsequent attacks is inversely proportional to the size of the organization, (c) Terrorist organizational growth is driven partly by recruitment processes associated with the production of new events. That is increase violent events lead to more recruitment which in turn leads to organizational growth. (d) As an organization carries out more attacks, the time between subsequent attacks decreases, and (e) the severity of new attacks depends on available labor pool and thus increases with organizational size, and with the number of attacks, respectively [1].

In a nonlinear differential equation model: "A Dynamical model of terrorism"[48], a new paradigm for studying terrorism by examining the "long-term dynamical evolution" of a terrorist organization when direct military and policing interventions are employed was proposed. The authors' methodology was to develop a dynamic model of terrorism in terms of the dynamics of the population of the individuals directly involve with terrorist activities - the terrorists, the susceptible, and the pacifists. The model, solved for fixed points with relevant sensitivity analysis yielded the conclusion that "a combination of military/police action and nonviolent/persuasive intervention would yield a fixed point with a lower terrorist population than with any one of these interventions in isolation"'[49]. Though the study makes the most comprehensive use of dynamical system analysis applied to terrorism research, however, it was criticized to be monadic. Like most mathematical surveys in terrorism, the study was observed by some CT scholars to be limited in scope and breadth, and neglecting the basics of political science conflict-peace theory.

In a similar system dynamics techniques, Chamberlain[11] sought a better understanding of how Al-Qaida is able to 'produce' terrorists that are willing to risk, and at times, sacrifice their lives and then deploy these individuals to carry out terrorist attacks. By graphically representing the cause and effect interactions of the Al-Qaida terrorist organization through stock-flow diagrams and causal loop diagrams, the author was able to develop a "historical behavior pattern for this organization". The author 
analysis was extended to the US CT strategies; to include funds allocations for the Department of Defense, Department of Justice, Department of Transportation, and the Department of Homeland Security. In conclusion, the author observed that "doing something, following either the current US strategy or the US preventive strategy is better than doing nothing at all (the Baseline Strategy)". By implication, the model asserted that "the post 9/11 US counter-terrorism strategy of the US is an effective approach to the global war on terrorism". Chamberlain[11] further predicted that, "regardless of the US strategy followed, Al-Qaida will still be able to conduct at least three additional terrorist attacks, resulting in at least 2,000 additional US citizen deaths before 2010”. This conclusion put the entire US security agencies at red alert. However, because this expected attacks was not forthcoming since author's postulation, terrorism scholars commented on the limitations of system dynamics techniques for predictive purposes.

Another effort in the application of differential equation to describe and model the behavior of terrorist organization was Gutfraind's[21] dynamic model, whose methodology was creating a very simple dynamic model of a terrorist organization structure from a human resources point of view; focusing on examining how the numbers of terrorist operatives in the organization change with time. In this work, the author evolved and solves analytically a system of two linear ODEs, whose result concluded that, "in a general system, his modeled terrorist organization, "would collapse if its strength and its pool of footsoldiers decline simultaneously". And in contrast, "a simultaneous decline in its strength and its pool of leaders is often insufficient and short-termed as well to guarantee the eminent collapse of the organization"'[21].

Perhaps, the presumed gap created by the above Gutfraind's[21] conclusion motivated Butler ${ }^{[7]}$ to attempt an analytical study of the viability and the indispensable hidden catalytic roles of the terrorist recruiters in the organization's dynamics. Butler's dynamic model: “Hezbollah: The Dynamics of Recruitment”[7], centered on deriving a differential equation model of Hezbollah's recruitment process, by blending the deterministic mathematical modeling techniques with qualitative techniques of case study analysis from the political science discipline. His monograph highlighted the logistic growth as a driver of adaptation for Hezbollah's recruitment process; hence the utility of using the logistic growth model to estimate the potential recruitment pool of susceptible youth's population in the absence of validated data was illustrated. However, while drawing analogy on the role of terrorist recruiters to that of catalytic enzymes in biochemical kinetics, Butler[7] evolved and solved analytically, a system of four non-linear ODEs popularly called "Michaelis-Menten equations of enzymes kinetics"[15]. These equations represent the dynamical evolution of four classes of terrorist operatives (the restless, the recruiters, the recruits and the radicals). The author's analytical results concluded that "the growth rate and strength of the Hezbollah terrorist organization under study (and indeed most terrorist organizations) is dependence on the number of recruiters; the number of recruits (foot-soldiers); the success rate of previous terrorist attacks to stimulate recruitment; and as well as funding and education to support and execute all of these activities by the various populations over time"[7]. To proffer solution to his identified terrorist's strength drivers, the author suggested that a reduction in "non-suicide violence through education, and the numbers of recruiters (in order of preference) may contribute to the degradation of recruiter's ability to conduct the recruitment process", and hence the collapse of the organization.

Furthermore, guided by the efficacy of credible intelligence gathering in ideal CT operation, the war of attrition model by Kress, \& Szechtman[37] was also developed. The model, also a differential equation model, dynamically addresses the relationship between intelligence gatherings; collateral casualties in the population during terror war of attrition; recruitment to the insurgency and reinforcement to the government force during CT operations. The author's aims was to examine the effect of the collateral damage that often occurs when large-scale US military operations take a high-force buck-shot approach toward eradicating terrorists' cells within a locality. The consideration was that such collateral damage caused to the general population resulting from poor human targeting, often result in mass killing of innocent civilians' population. This may generate adverse response against the government and security operatives and create popular support for the insurgents; which may result in higher recruitment to the insurgency. Conventionally, collection of sufficient and credible intelligence to build up detail knowledge of the location of terrorists or threats to a country's security should be at the heart of every government's security and intelligence experts. Intelligence operations protect society against the threat of terrorism. "Without sufficient and credible intelligence, governments cannot protect their citizens. Without accurate knowledge of who the terrorists are, governments cannot know where they are. Without knowing where the suicide bombers are, the security agency cannot prevent planned suicide bombing attacks"'[22,23]. Therefore, sufficient and credible intelligence is the heart and soul of counter-terrorism operations.

Applying conventional warfare dynamic concept[38], Kress and Szechtman[37] evolved and solved analytically, a system of two ODEs describing the interaction between two explicit players in CT operation (the insurgents and the government forces), that battled each other, at the detriments of one implicit player (the general population) that are usually victims of government's military offensives and provides new recruits to the insurgency. From their findings, the authors concluded that "government would always lose if there is no reinforcement to its force because the intelligence capabilities of the government degrade with the 
attrition of its force, causing many innocent casualties and indirectly strengthening the insurgency which eventually takes over". Proffering solution to their identified error, the authors suggested that "an influence campaign operation could reverse this reinforcing loop[37].

However, without specifying the type or details of their suggested influence operation, the authors' expectation is that, with a well-articulated and credible influence campaign operations, the numbers of terrorist defectors would increase. An increased numbers of defectors would provide more accurate intelligence for smart-targeting of insurgent locations, and that civilian deaths could be reduced if the killing were more selective. Though, Kress and Szechtman[37] recognize that terror war of attrition is problematic and cost oriented, however, they maintained that increasing killing accuracy is the best-case scenario for ideal CT measures. However, the authors concluded that "government cannot totally eradicate the insurgency by force, the best it can do is to contain it at a certain fixed level". Kress and Szechtman[37] also recognized that ideology might play a role in waging an antiinsurgent "war of attrition" but excluded ideology from their model because it was too difficult to measure.

Furthermore, given the high correlation between ideological strength and insurgent community size, and given insurgents' employment of ideology as a currency to recruit supporters; the size of the insurgent community may serve as a proximal metric of its ideological strength. Therefore, as an extension of the idea of "smart-target" eradication of ideology, Weaver[52] developed a dynamic model whose methodology was an extension of Kress and Szechtman[37] model; by adding the concept of insurgent ideologies as a CT target. Moving the discussion beyond the "reduction of killing" approach, the author though transparent in her approach, uses system parameters and functions which were highly notional. Since the author foresaw that a model could test alternative influence campaigns, she extended the terror war of attrition model[37] to include the impact of the influence campaign operations, by defining "defection messaging” as an anti-insurgent influence campaign that could target ideology[51]. She however, was not aware of any empirically supported models of such an intervention.

Motivated by the above landmarks exploit of differential equation models in terrorism research, the present model "Optimal Human Resources Allocation in Counter-Terrorism (CT) Operation: A Mathematical Perspective”, seek to address the global question in terror war of attrition - when fighting a given terrorist organization, what targets would yield an optimal result? The study, a preliminary work to my $\mathrm{PhD}$ (Applied Mathematics) research study and a complementary extension of Gutfraind's[21] and Butler's[7] dynamic model, hypothesize a formal identification and inclusion of the terrorist recruiters' class and their recruitment institutions as a pragmatic target for ideal CT operation. In the study, we present a mathematical deterministic model of a terrorist's organizational structure consisting of three classes of operatives (leaders, foot-soldiers and recruiters). The model which also uses a set of coupled differential equations to describe and model the behaviour and the structural evolution of a terrorist organization is aimed at examining how the numbers of terrorist operatives in the organization changes over time under a given CT measure; thus, casting our empirical-based knowledge in precise mathematical language.

Our target is to derive an analytical model of CT measures that would help to degrades or render dysfunction a given terrorist organization, while also serving as a quantitative metrics for evaluating the decree of accomplishment or otherwise of a given CT operations. Refinement of our ideas should enable security agencies to able to state emphatically, for example, that they are $85 \%$ certain that they have destroyed or captured or weaken the strength of the terrorist group under investigation; and that there is still a $15 \%$ chance that terrorists might commit another deadly attack. The study has the potential to inform both scholars and CT policy makers on the optimal strategy for allocating the available human resources towards effective CT measures. The simplicity of our model should hopefully make it an attractive target for extensions by enterprising students of military operations Research (OR) and dynamical systems analysis. The study also has the synergy to demonstrate that, terrorism though complex and divergent a socio-economics system is an area where mathematical methods and off-course differential equations can make an impact in a variety of targets and research problems.

\subsection{THE MATHEMATICAL MODEL}

To develop our model, we consider numerical strength $S(t)$ of our terrorist organization at any time $(t)$ to consist of the population of three potential classes of operatives; Leaders $\mathrm{Y}(\mathrm{t})$, Foot-soldiers $\mathrm{X}(\mathrm{t})$ and recruiters $\mathrm{Z}(\mathrm{t})$. Let the differential derivatives of the variables; $Y^{\prime}(t), X^{\prime}(t)$ and $Z^{\prime}(t)$, represent their respective rate of growth of the operatives. The terrorist leaders $Y(t)$ though often fewer in number than operatives, represent a more formidable and valuable members of the group. They include the experienced managers, operation commanders, weapon experts, financiers and even political and religious leaders who are key stakeholders and decision makers in the organization. In the conventional ethno-politically driven terrorism, the organizations place comparatively greater premium on the security and defence of its leadership class. Hence, their comparatively formidable status and inaccessibility to proper targeting by any orchestrated CT measures. The leaders $Y(t)$, with their valuable skills, wealth of experience and financial sovereignty contribute more to the overall strength $S(t)$ of any organization than an equivalent number 
of other operatives. This comparatively high premium placed on the status and role of the leaders can be model as more weight (say $m>1$ ) than other variables[21]. Mathematically,

$$
S(t)=m Y(t)+X(t)+Z(t)
$$

\subsection{The Birth Process of the Organization}

(a) The leaders: Theoretically, from the history of Al-Qaeda, Hezbollah, ISIS and other terrorist organizations, the pool of terrorist leaders and experts $Y(t)$ grows primarily when foot-soldiers acquire battlefield experience or receive training (internally, or in terrorist-supporting states[24,25,33]. Consequently, the pool of terrorist leaders $Y(t)$ is provisioned with new leaders at a rate proportional to the number of foot soldiers (i.e. $Y^{\prime}=p X(t)$ ), (where the proportionality constant $(p)$ denotes the "promotion" process).

\section{(b) The Foot-soldiers}

Unlike the dynamic of leaders, research also shows that the growth in the number of terrorist foot-soldiers (rank-and-file) $X(t)$ through recruitment process $(r)$ is driven primarily by two factors, (i) the intensity and success rate of terrorist propaganda, and (ii) effect of blowback action occasioned by the collateral damages and mass killing of innocent civilian population during military offensive against terrorists' cells within a locality. This often incites the spirit of disaffection and animosity among the disaffected youth population (the source of new insurgents), and, hence causing a "blowback action". The blowback action provoke "Herostratos syndrome" in the disaffected youth population. This help to pump-up new recruits and even increasing the number of new insurgents groups[4,6,53]. Thus, the growth in the number of terrorist foot-soldiers $X(t)$ varies with the strength $S(t)$ of the organization and with the number of commissioned recruiters $Z(t)$ as well as the recruitment and training facilities (i.e. $X^{\prime}=r S(t)+c Z(t)$ ), (where the proportionality constant (c) denote the "commission" process). This assumption capture the often seen cycle where every military attacks leads to greater recruitment (increase $(r)$ ) which leads to greater strength (increase $S(t))$ and more attacks from the terrorist ${ }^{[1],[11],[17,18] 49]}$.

\section{(c) The Recruiters}

Research also shows that the growth in the number of potential terrorist recruiters, $Z(t)$ increases primarily when "non-suicide" ex-jihadists acquire training by radical religious clerics, or socio-cultural or clandestine organization; usually funded by external states or financially sovereign individuals[7]. Hence, the increase in number of terrorist recruiter varies with the strength, $S(t)$ of the organization and with the number leaders, $Y(t)$ in the organization $\left(i . e . Z^{\prime}=c S(t)+p Y(t)\right)$ This process is termed “commission" $(c>0)$.

\subsection{The Death Process of the Organization}

The growth rate of terrorist operatives are often opposed by two processes: (i) internal personnel loss due to demotivation, fatigue, desertion as well as in-fighting and splintering[26]. This phenomenon is modeled as a loss of a fraction, $(d>0)$ of the number of operatives per unit time. (ii) Counter-terrorism measures targeted specifically at arresting, assassinations, kidnapping and as well as efforts to disrupt communications, financial asset and threat to force the operatives into long-term inactivity. We modeled this as a deduction of a fixed fraction, say, $(\alpha>0, \omega>0$, and $\sigma>0)$, per unit time from the respective operatives. Mathematically:

$$
\left.\begin{array}{rl}
Y^{\prime} & =p X(t)-(d+\alpha) Y(t) \\
X^{\prime} & =r S(t)+c Z(t)-(d+\omega) X(t) \\
Z^{\prime} & =c S(t)+p Y(t)-(d+\sigma) Z(t)
\end{array}\right\}
$$

\subsection{Assumptions of the Model}

The model is predicated on the following assumptions: (i.) On the average, the numerical strength of a terrorist organization at any interval of time is nourished by the combined processes of promotion $(p>0)$, recruitment, $(r>0)$ and commission $(c>0)$ and drained through desertion $(d>0)$ and CT measures $(\alpha, \omega, \sigma)$ on the respective operatives.

(ii.) Once a foot-soldier $X(t)$ is promoted to leadership $Y(t)$ cadre, a new foot-soldier is recruited as a replacement. If in some organizations such recruitment isn't automatic, then the current model is still valid for these organizations as long as $(r>p)$

(iii.) 'Similarly, once a leader $Y(t)$ is assigned a recruiters' $Z(t)$ responsibility, a new foot-soldier $X(t)$ is promoted to a leadership position as a replacement. Also if in some organizations such promotion isn't automatic, then the current model is still valid for these organizations as long as $(p>c)$. In any case the drain due to promotion is marginal because foot-soldiers are far more numerous than leaders even in relatively "top heavy" organizations.

(iv.) The ingenuity of recruiters $Z(t)$, like a catalytic enzyme, to speed up the recruitment and transformation process of the recruits into radical foot-soldiers without being directly targeted by a viable CT measures, allows terrorist organizations to grow through a sustained support-base that is constantly supplying new personnel for the possible conversion into radical footsoldiers[7]. 
(v.) As implicit assumptions, the model also assumes:

(a) A state of stable gradual change, such that the effect of one terrorist or interdiction process is smoothed. This should be acceptable in all cases where the terrorist organization is not very small and thus changes are not very stochastic.

(b) That an organization's growth is constrained only by the available manpower and factors such as money or weapons do not impose an independent constraint.

(c) That the growth in foot-soldiers is not constrained by the availability of potential recruits since in most ideologically driven terrorism, willing recruits are always plentiful.

Combining equation (1), equation (2) and the above array of assumptions, we arrived at our mathematical model represented by the system of three ODEs:

$$
\left.\begin{array}{rl}
Y^{\prime}= & p X(t)-(d+\alpha) Y(t) \\
X^{\prime}= & r m Y(t)+(r-d-\omega) X(t)+(r+c) Z(t) \\
Z^{\prime}= & (m c+p) Y(t)+c X(t)+(c-d-\sigma) Z(t) \\
& (m>1 ; 0<p, r, c, d, \alpha, \omega, \sigma<1)
\end{array}\right\}
$$

Subject to the initial value conditions:

$$
Y\left(t_{0}\right)=Y_{0} ; X\left(t_{0}\right)=X_{0} ; Z\left(t_{0}\right)=Z_{0}
$$

Research findings and journalistic accounts of how Al-Qaida and its affiliates have developed over the last decades, indicates that a notional terrorist organization under the influence of an ideal interdiction measure, can at-most be nourished at an average rate of $3 \%$ per leaders, $12 \%$ per foot-soldiers and $1 \%$ per recruiters annually and drained at an average rate of $3 \%$ per class of operatives through internal personnel loss, and 20\% per class through CT measure[7,21,49,51].

Table 1: Model Variables, Parameters and their Description

\begin{tabular}{|c|l|c|}
\hline Parameters & \multicolumn{1}{|c|}{ Description } & Values \\
\hline$Y(0)$ & Number of terrorist leaders at time $(t)$. & 5.0 \\
$X(0)$ & Number of terrorist foot-soldiers at time $(t)$. & 120 \\
$Z(0)$ & Number of terrorist recruiter at time $(t)$. & 2.0 \\
$m>1$ & Weight of the leadership (over other operatives), & 10.0 \\
$0<p<1$ & Proportion of foot-soldier promoted to a leader, 3\% & 0.03 \\
$0<r<1$ & Proportion of foot-soldiers recruited, 12\% & 0.12 \\
$0<c<1$ & Proportion of commissioned recruiters 1\% & 0.01 \\
$0<d<1$ & Proportion of internal personnel drain, 3\% & 0.03 \\
$0<\alpha<1$ & Proportion of interdicted leaders, 20\% & 0.2 \\
$0<\omega<1$ & Proportion of interdicted foot-soldiers, 20\% & 0.2 \\
$0<\sigma<1$ & Proportion of interdicted recruiters, 20\% & 0.2 \\
\hline
\end{tabular}

\subsection{Analysis of the Model}

Before studying the solution paths of equation (3), in this section, we first performed the mathematical analysis to find the terrorist's equilibrium points and their local stability. To determine the equilibrium points, let the dynamic of each population in equation ( 3 a) equals zero, (i.e. $\left.Y^{\prime}=X^{\prime}=Z^{\prime}=0\right)$ :

$$
\left.\begin{array}{l}
0=p X(t)-(d+\alpha) Y(t) \\
0=r m Y(t)+(r-d-\omega) X(t)+(r+c) Z(t) \\
0=(m c+p) Y(t)+c X(t)+(c-d-\sigma) Z(t)
\end{array}\right\}
$$

At this state, we assume that there is no terrorist activity, and thus, no interdiction process except the internal personnel drain. This proves that $E_{0}=(Y(t), X(t), Z(t))=(0,0,0)$ is the terrorist-free equilibrium state (TFES) of the model. To determine the stability of the equilibrium state by the linearization stability method, we have that

$$
\left.\begin{array}{l}
f_{1}=p X(t)-(d+\alpha) Y(t) \\
f_{2}=r m Y(t)+(r-d-\omega) X(t)+(r+c) Z(t) \\
f_{3}=(m c+p) Y(t)+c X(t)+(c-d-\sigma) Z(t)
\end{array}\right\}
$$

Therefore the Jacobian matrix is 


$$
J=\left[\begin{array}{ccc}
-(d+\alpha) & p & 0 \\
r m & (r-d-\omega) & (r+c) \\
(m c+p) & c & (c-d-\sigma)
\end{array}\right]
$$

Therefore,

$$
|J-\lambda I|=\left|\begin{array}{ccc}
-(d+\alpha)-\lambda & p & 0 \\
r m & (r-d-\omega)-\lambda & (r+c) \\
(m c+p) & c & (c-d-\sigma)-\lambda
\end{array}\right|=0
$$

Solving the expression (5) for $\lambda$, using MATLAB, we also have

$$
\left.\begin{array}{l}
\lambda_{1}=\frac{1}{6}\left(48 \alpha r \sigma+48 \alpha \omega c-48 \alpha \omega \sigma+108 m p c^{2}+84 \alpha c^{2}+108 r p^{2}+108 c p^{2}+\cdots\right) \\
\lambda_{2}=\frac{-1}{12}\left(48 \alpha r \sigma+48 \alpha \omega c-48 \alpha \omega \sigma+108 m p c^{2}+84 \alpha c^{2}+108 r p^{2}+108 c p^{2}+\cdots\right) \\
\lambda_{3}=\frac{-1}{12}\left(48 \alpha r \sigma+48 \alpha \omega c-48 \alpha \omega \sigma+108 m p c^{2}+84 \alpha c^{2}+108 r p^{2}+108 c p^{2}+\cdots\right)
\end{array}\right\}
$$

By Routh-Hurwitz criteria, $\lambda_{1}>0, \lambda_{2}<0$, and $\lambda_{3}<0$, the terrorist free equilibrium state $E_{0}=(0,0,0)$ is marginally stable; a common characteristics of most terrorist organizations.

\subsection{Numerical Simulation}

Given the experimental data set on Table-1 above, to address our global research question, we carry out the analysis of our model (3), under five experimental regimes representing five interdiction strategies. Mathematically, the solution path of each sub-model corresponds to the question of whether at some future time the value of the variables $Y(t), X(t)$ and $Z(t)$ would reach zero, i.e.

$$
\left.\begin{array}{rl}
\lim _{t_{0} \rightarrow t} Y(t)=\lim _{t_{0} \rightarrow t} X(t) & =\lim _{t_{0} \rightarrow t} Z(t)=0 \\
& \Rightarrow \lim _{t_{0} \rightarrow t} S(t)=0
\end{array}\right\}
$$

For experimental analysis, we consider a notional terrorist group with initial strength of 5 leaders, 120 foot-soldiers and 2 recruiters. Research findings and journalistic accounts of how Al-Qaida and its affiliates developed and grows over the last decades indicate that; constraint by the heterogeneity of the terrain, the asymmetric nature of the warfare, the insufficient credible intelligence and as well as limited human/material resources at the disposal of CT operatives and decision makers; a notional terrorist organization under the influence of an orchestrated CT measure can at-most be nourished at an average rate of 3\% per leaders, $12 \%$ per foot-soldiers and $1 \%$ per recruiters annually. This dynamics is hampered by internal personnel drained factor of $3 \%$ and CT measure of $20 \%$ per class of operatives[7,8,11,21]. Thus, in this analysis, we are hypothesizing a positive incentive measures (Carrot) that would boost the internal personnel drain factor $(d)$ to at-least $20 \%$.

3.4.1 Strategy-1; Zero CT measures $(d=0.03, \alpha=\omega=\sigma=0)$ : Suppose in the first 5-years of the existence of a terrorist organization, the terrorist and their violent activity were either not countered or countered with minimal effort of internal personnel drain; then the solution of system (3) is given by figure-2(a),(b),(c) and (d) below.
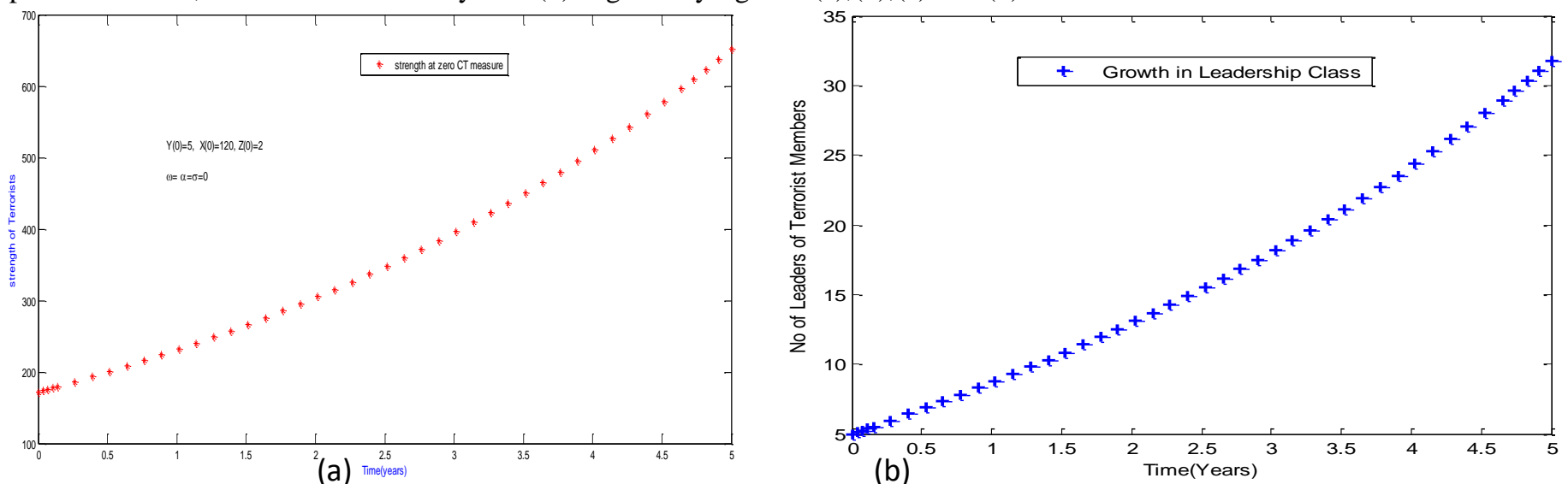

Figure-2(a, b): Terrorist Evolution under Strategy-1

Represented graphically above in Figure-2, are the solution trajectories of the system of equations (3), under zero CT measures. Figure 2(a) above shows that under this strategy, the overall strength of the organization grows exponentially from the initial 172 operatives to 661, representing an increase of 97.8 operatives annually. Figure 2(b) above shows the exponential growth of the leadership pool from 5 operatives to 32, representing an increase of 5.4 operatives annually. Figure 2(c) below represents the exponential growth of the foot-soldiers population from 120 operatives to 312, representing an increase of 38.4 operatives annually. Figure 2(d) below also gives an exponential growth of the recruiters' population from the initial 2 operatives to 19, representing an increase of 3.4 operatives annually. Thus, in the absence of a viable interdiction process except the inherent internal personnel drain $(d=0.03)$ due to demotivation, fatigue, desertion as well as in-fighting and splintering, all the operatives' population grows exponentially. 
3.4.2 Strategy-2: Interdiction targeted at Leaders and Foot-soldiers simultaneously: $(d=0.03, \omega=\alpha=0.2, \sigma=0)$. Suppose the interdiction was targeted only at the leaders and foot-soldiers classes simultaneously; while undermining the influence of the recruiters' class. The solution paths of equations (3) under this strategy are as shown in figure-3, below
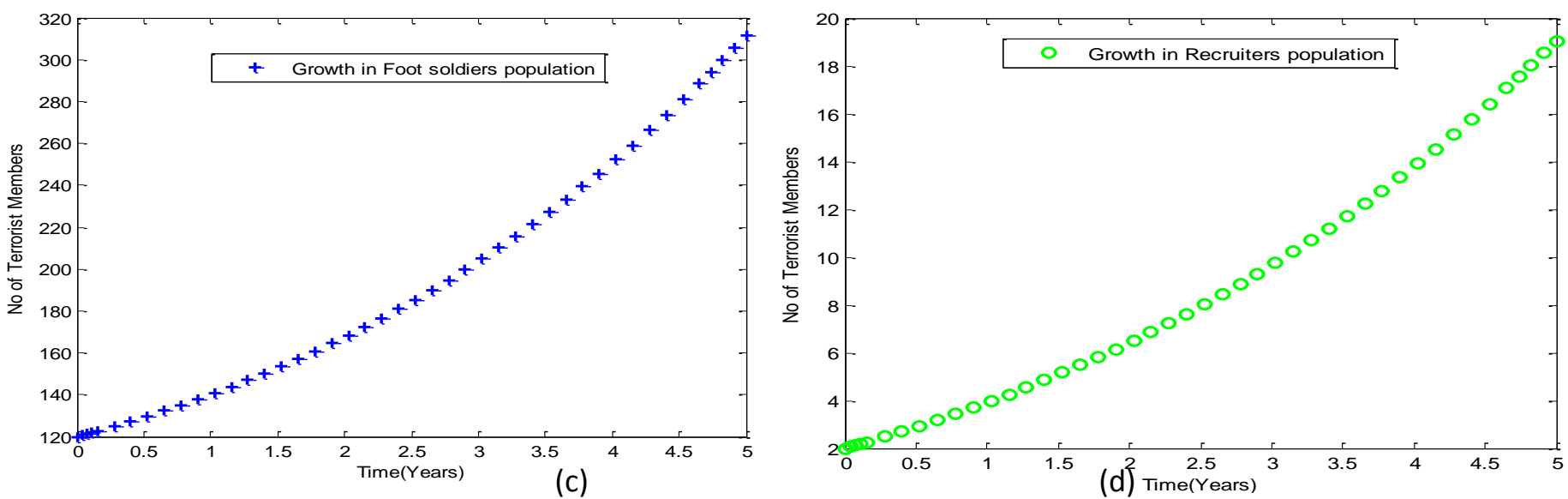

Figure-2(c, d): Terrorist Evolution under Strategy-1

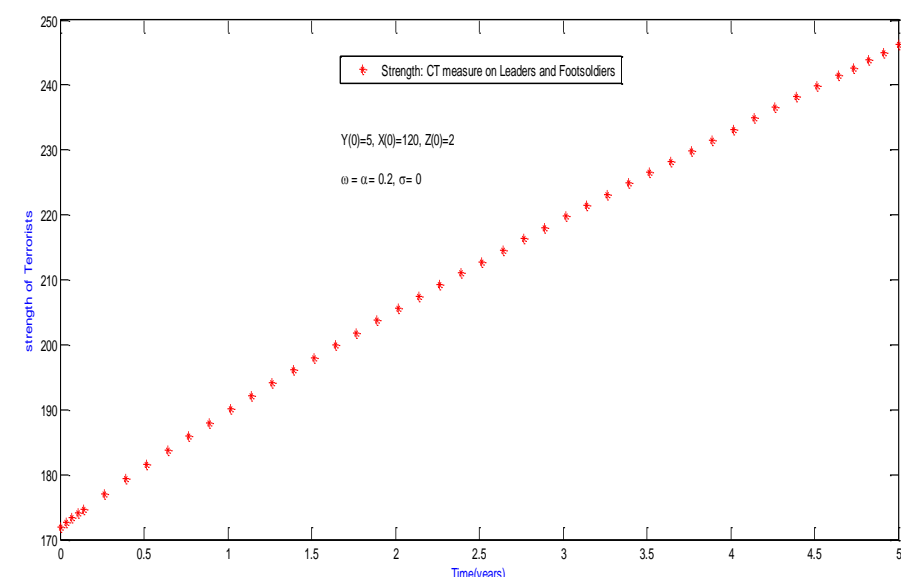

(a)

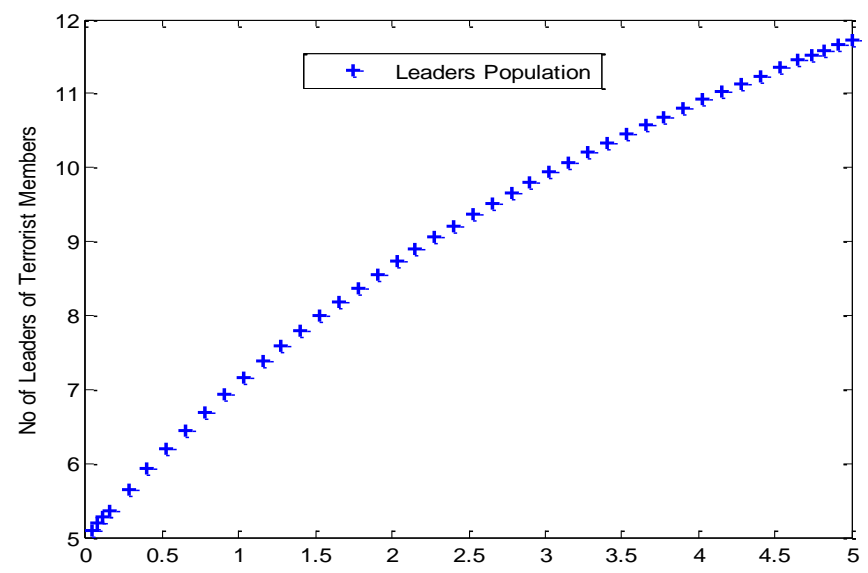

(b)

Figure-3(a, b): Terrorist Evolution under Interdiction Strategy-2.

The figure 3(a) shows the parabolic growth of the overall strength of the organization from the initial 172 operatives to 245.5 , representing an increase of 14.7 operatives annually. In figure 3(b), a parabolic growth pattern is also depicted by the leadership class, (from 5 operatives to 11.8 , representing an increase of 1.36 operatives annually). In figure 3(c) below, the foot-soldiers population though experienced a drastic initial decline from 120 to 112 within a period of 2.5 years; eventually recuperate rapidly to a population of 115.9 within another period of 2.5 years (representing increase of 1.56 operatives annually). In figure 3(d) below, the linear growth in the recruiters' population is unperturbed (from 2 operatives to 11.6, representing an increase of 1.92 operatives annually) since it was not directly under a viable interdiction process, except the inherent internal personnel losses.
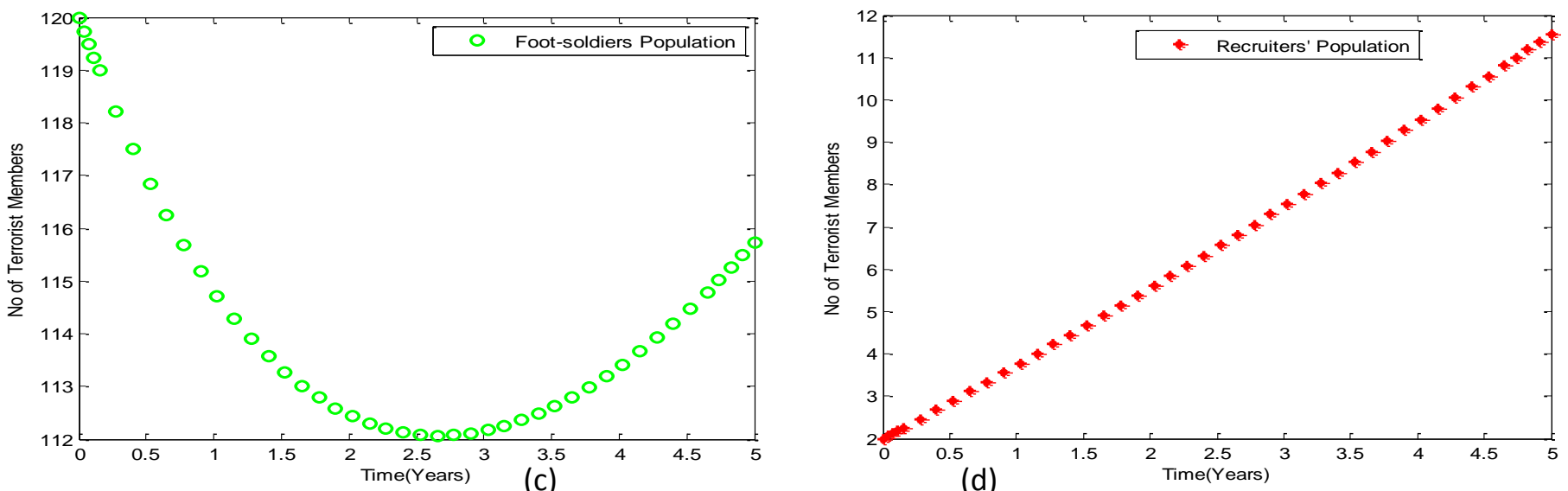

Figure-3(c,d): Terrorist Evolution under Interdiction Strategy-2 
3.4.3 Strategy-3: Interdiction targeted at Leaders and Recruiters Simultaneously; $(d=0.03, \omega=0, \alpha=\sigma=0.2)$. Suppose the interdiction is targeted only at the leaders and recruiters classes simultaneously; while undermining the influence of the foot-soldier class. The solution paths of system (3) are represented by figure-4, below. The figure 4(a) below shows the growth in the overall strength of the organization from the initial 172 operatives to 479.6, representing an increase of 61.52 operatives annually. In figure 4(b) above the leaders' population still exhibits a positive exponential growth from 5 operatives to 19, representing increase of 2.8 operatives annually; notwithstanding the dual interdiction processes of inherent internal personnel drain and CT measures. In figure 4(c) below, the foot-soldiers population also increases exponentially, from 120 operatives to 279 , representing an increase of 31.8 operatives annually. In figure 4(d) below, the growth in recruiters' population also increases exponentially unperturbed from 2 operatives to 10.2, representing an increase of 1.62 operatives annually.
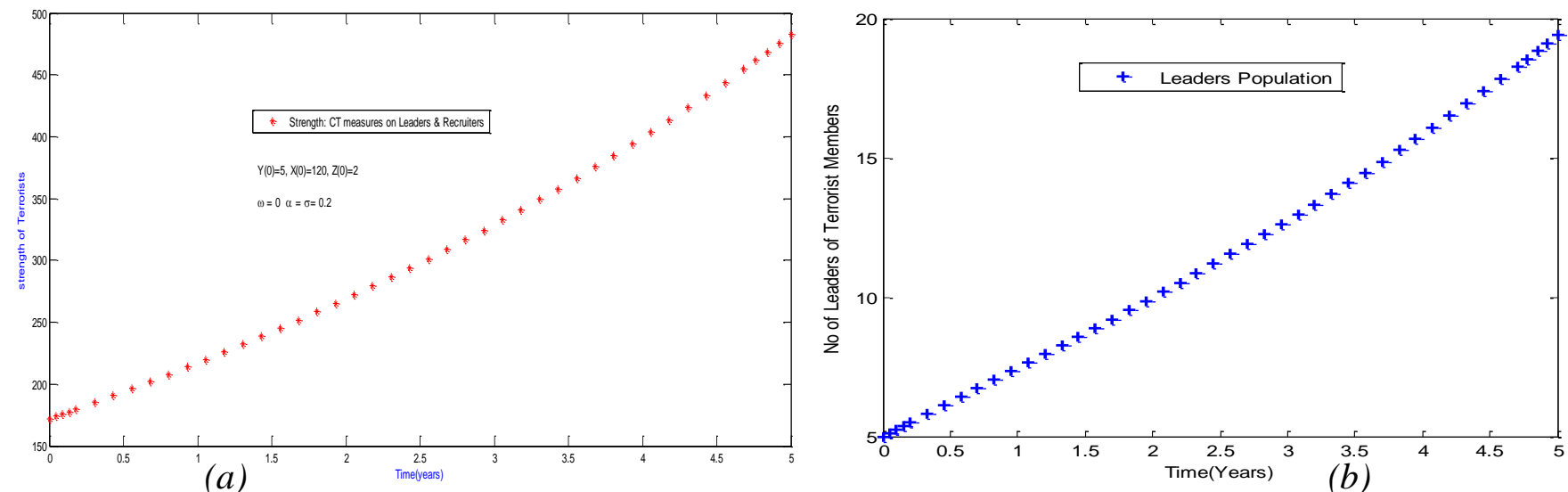

Figure-4(a, b): Terrorist Evolution under Interdiction Strategy-3
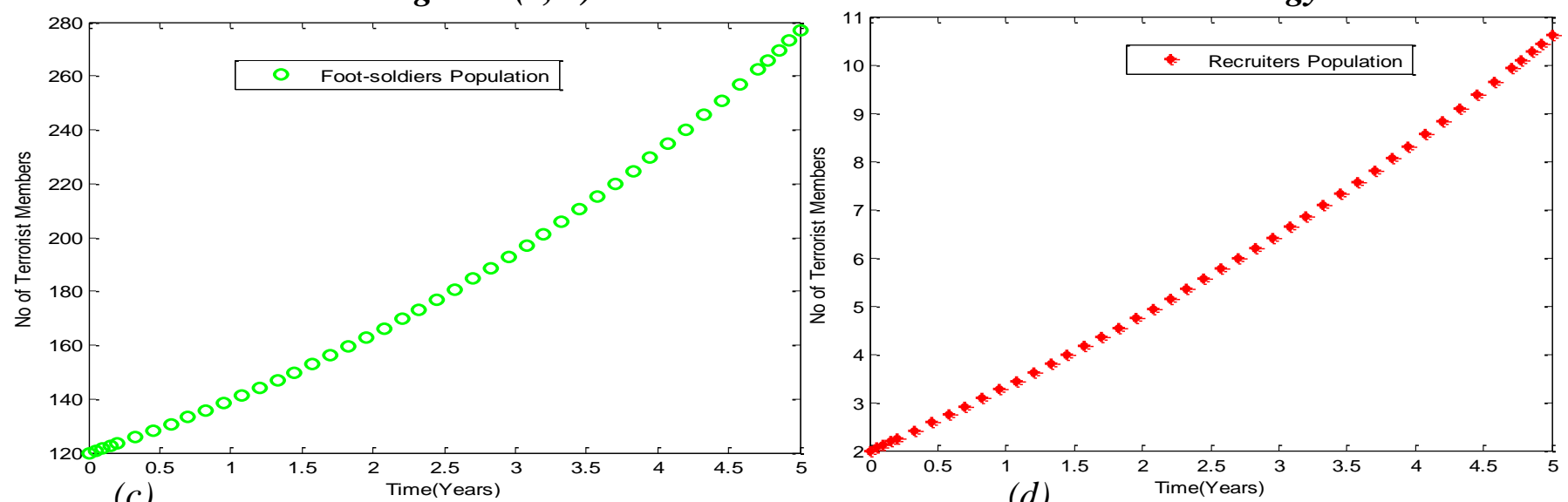

Figure-4(c,d): Terrorist Evolution under Interdiction Strategy-3

3.4.4 Strategy-4: Interdiction targeted at Foot-soldiers and Recruiters simultaneously, $(d=0.03, \omega=0.2, \alpha=0, \sigma=$ 0.2). Suppose the interdiction is targeted only at the foot-soldiers and recruiters' classes simultaneously; while undermining the influence of the leadership class. The solution path of equations (3) is as given by figure-5, below.
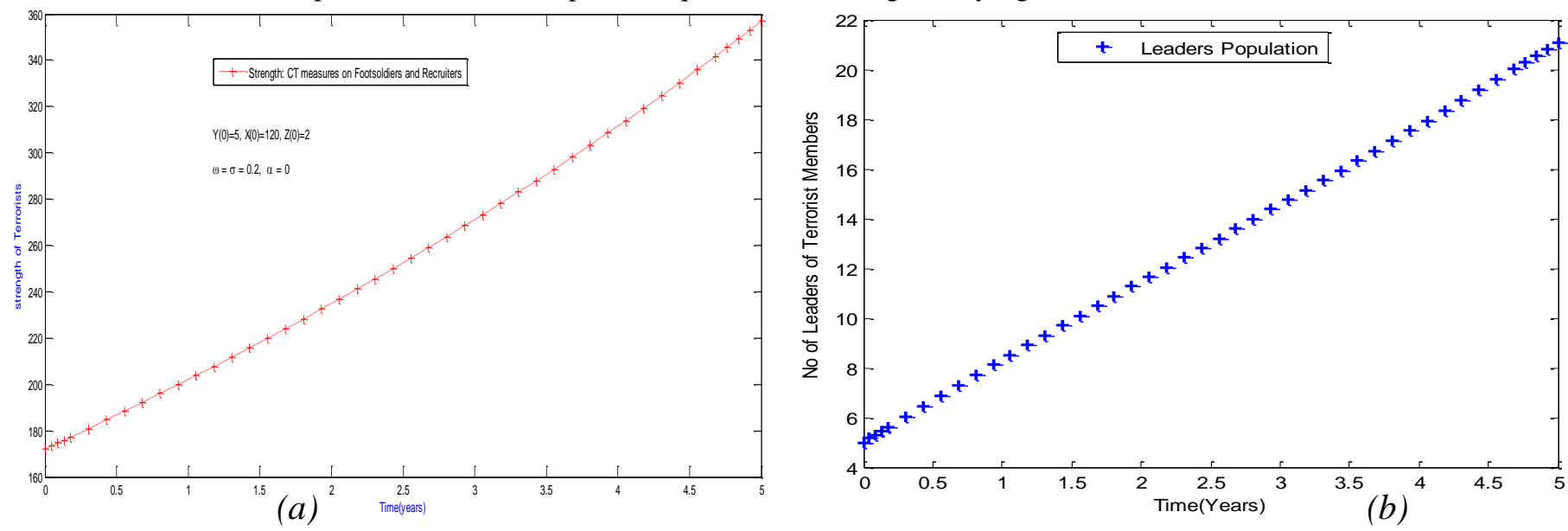

Figure-5(a,b): Terrorist Evolution under Interdiction strategy-4 
The figure 5(a) above shows the growth in the overall strength of the organization from the initial 172 operatives to 353.8 , representing an increase of 36.36 operatives annually. In figure 5(b) above the leaders' population still exhibits a positive linear growth from the initial 5 operatives to 21, representing increase of 3.2 operatives annually. In figure 5(c) below, the foot-soldiers population exhibits an initial marginal decline from 120 to 115 within a period of 1.5 years but eventually recuperate (to 135 within the next 3.5 years, representing an increase of 5.7 operatives annually), through the various recruitment indicators and instigators. In figure 5(d) below, the linear growth in recruiters' population also experienced a high increment from 2 operatives to 8.8 , representing an increase of 1.36 operatives annually.
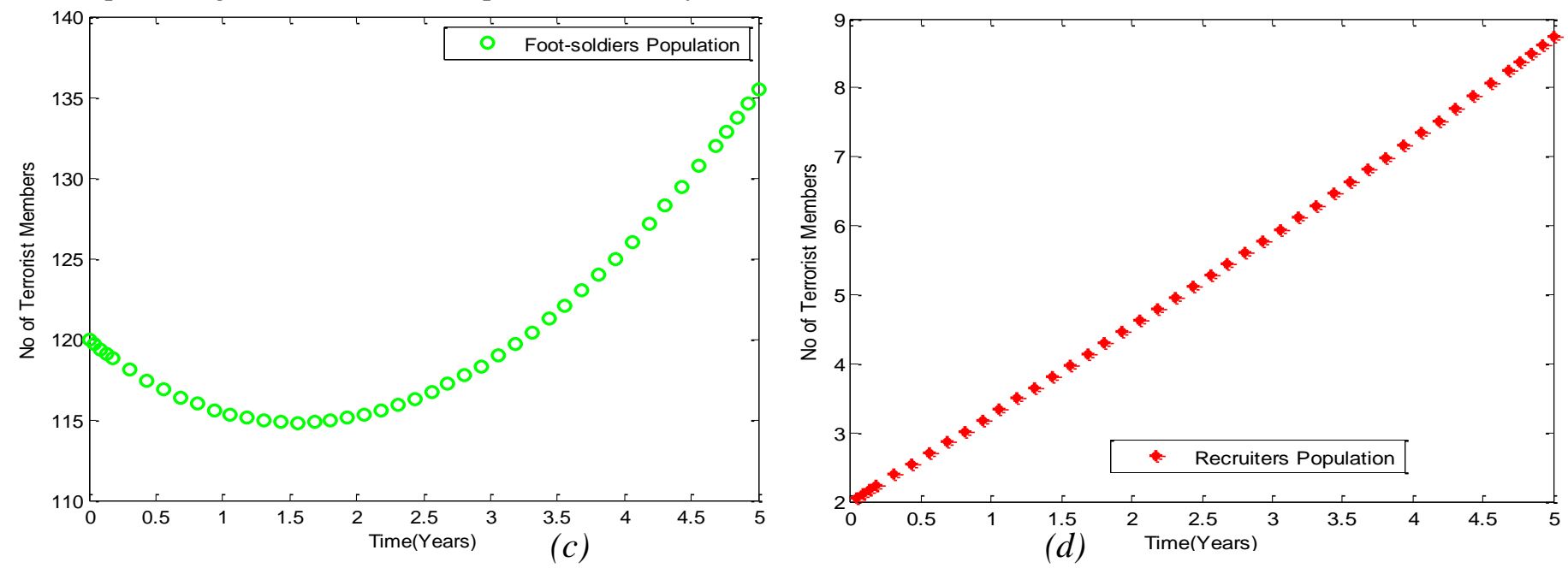

Figure-5(c,d): Terrorist Evolution under Strategy-4

3.4.5 Strategy-5: Interdiction targeted at Leaders, Foot-soldiers and Recruiters Simultaneously, $(d=0.03, \omega=\alpha=\sigma=$ 0.2). Suppose the interdiction now target the three classes of operatives (leaders, foot-soldiers and recruiters) simultaneously. The solution path of equations (3) is as given in figure-6, below.
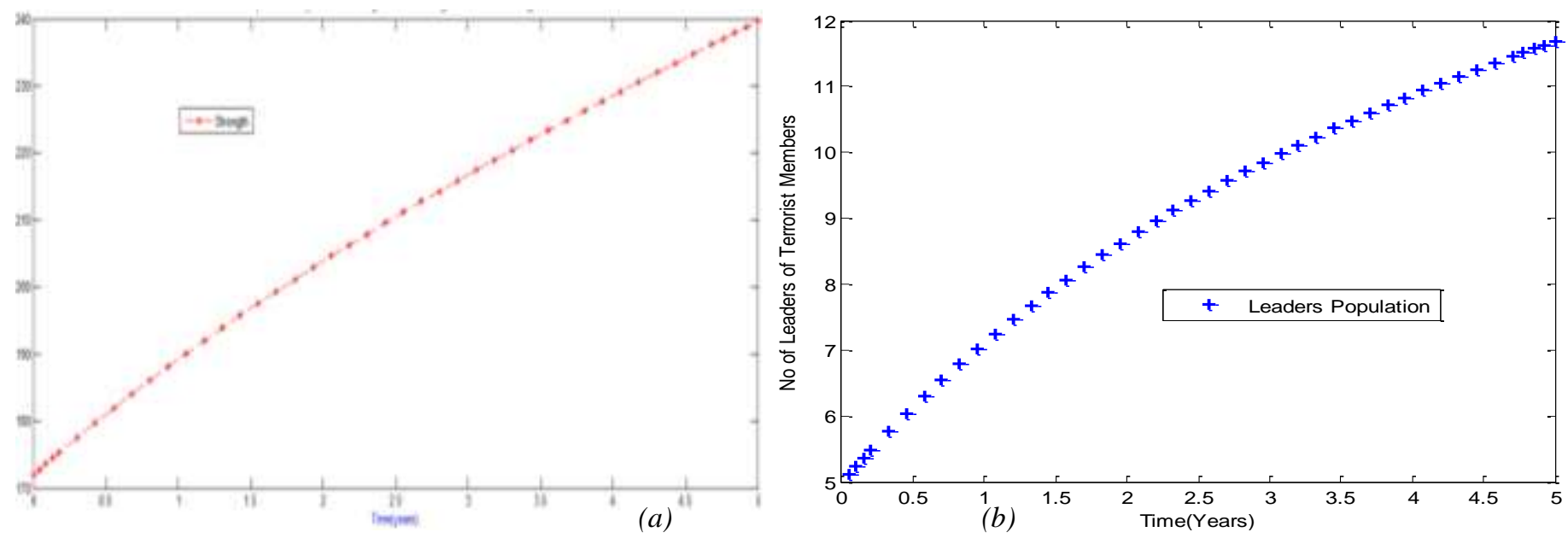

Figure-6(a, b): Terrorist Evolution under Strategy-5

The figure 6(a) above shows the growth in the overall strength of the organization from the initial 172 operatives to 238.8 ; representing an increase of 13.36 operatives annually. In figure 6(b), the leaders' population shows a parabolic growth from 5 operatives to 11.7 , representing an increase of 1.34 operatives annually, though targeted by the relevant interdiction measures. In figure 6(c), the foot-soldiers' population as often, experiences a sharp initial decline from 120 operatives to 112 within a period of 2.5 years but marginally recuperates through the various recruitment instigators to 114.7 within the next 2.5 years, representing an increase of 1.08 operatives annually. In figure 6(d), the population of the recruiters' class also appreciates marginally from 2 operatives to 7 , representing an increase of 1.0 operative annually. 
International Journal of Advances in Scientific Research and Engineering (ijasre), Vol 5 (1), January-2019
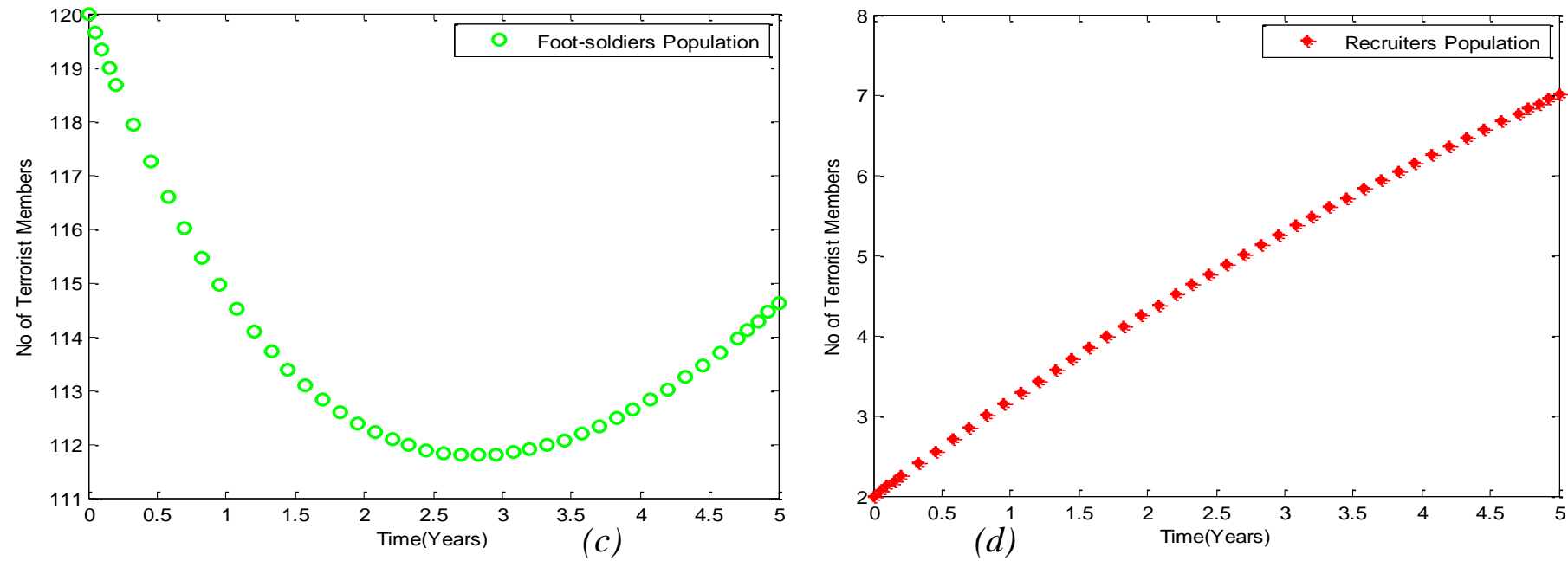

Figure-6(c, d): Terrorist Evolution under Strategv-5

\subsection{Comparative Analysis of the Terrorist Strength}

To hypothesize an optimality of each strategy, we carry out a comparative analysis of the terrorists' strength (figure 7) and as well as its evolution characteristics under the five strategies (figure 8).

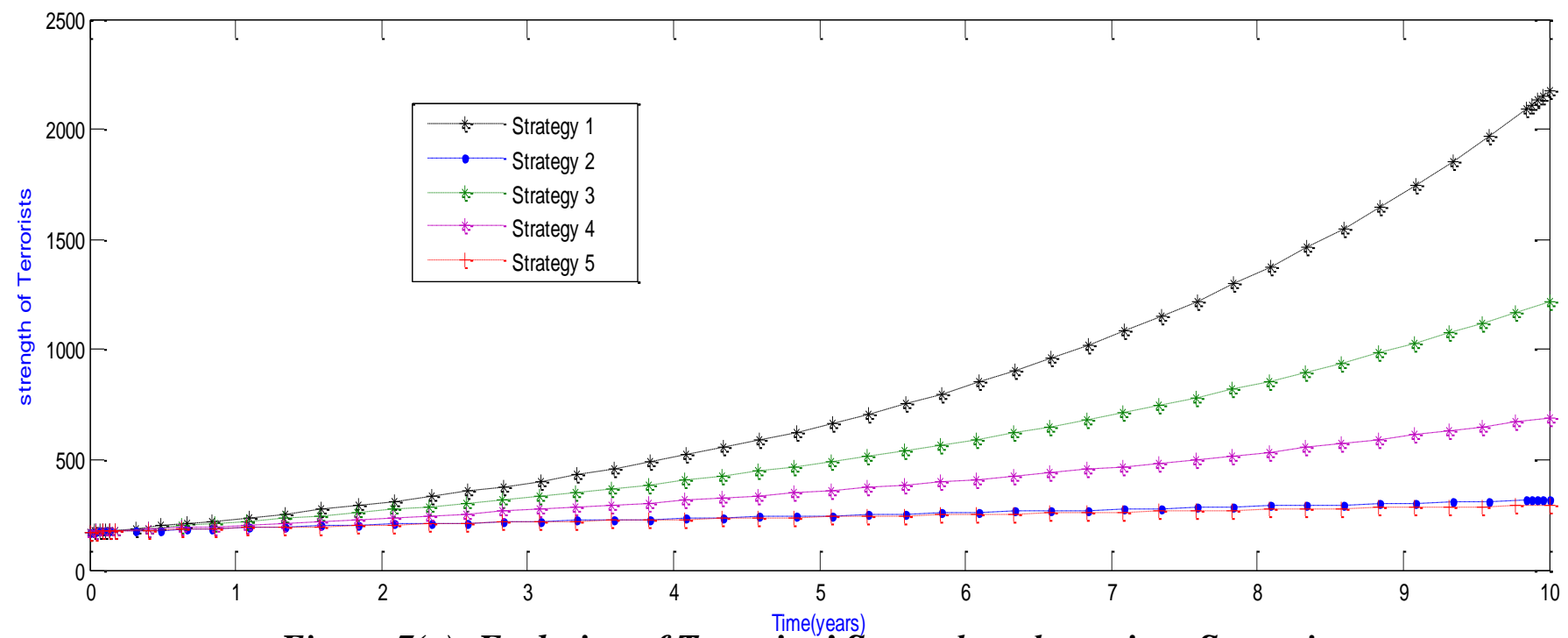

Figure-7(a): Evolution of Terrorists' Strength at the various Strategies

The figure-7 above shows that strategy (5) and (2) yield the least terrorist strength of 293.8 and 318 operatives respectively, representing an increase of only 12.18 and 14.6 operatives annually, respectively. While terrorist strength in strategy (1), (3) and (4) are comparatively highest, higher and high in that order, with 2171, 1220 and 688.6 operatives, representing an increase of 197.9, 104.8 and 51.66 operatives respectively, annually.

3.5.1 The Variability of Organization's Growth Rate with CT Strategy: Table 2 below shows a summary of the characteristic of the organization's growth and interdiction rates with respect to the CT strategies. These are graphically represented in figures 8 , below. 
International Journal of Advances in Scientific Research and Engineering (ijasre), Vol 5 (1), January-2019

Table 2: Variability of the Organizational Dynamics with CT Strategies

\begin{tabular}{|lccccc|}
\hline \multicolumn{1}{|c|}{ Variable } & Leaders & Foot-soldiers & Recruiters & STRENGTH \\
\hline Initial Population & 5.0 & 120 & 2.0 & 172 \\
Strategy-1: Zero CT & 32 & 312 & 19 & 661 \\
Strategy-2: Y(t)+X(t) growth & 11.8 & 115.9 & 11.6 & 245.5 \\
Strategy-3: Y(t)+Z(t) growth & 19 & 279 & 10.2 & 479.6 \\
Strategy-4: X(t)+Z(t) growth & 21 & 135 & 8.8 & 353.8 \\
Strategy-5: X(t)+Z(t) growth & 11.7 & 114.7 & 7.0 & 238.8 \\
Strategy-1: Growth rate (\%) & $108 \%$ & $32 \%$ & $170 \%$ & $56.9 \%$ \\
Strategy-2: Growth rate (\%) & $27.2 \%$ & $-0.68 \%$ & $96 \%$ & $8.55 \%$ \\
Strategy-3: Growth rate (\%) & $56 \%$ & $26.5 \%$ & $82 \%$ & $35.8 \%$ \\
Strategy-4: Growth rate (\%) & $64 \%$ & $2.5 \%$ & $68 \%$ & $21.1 \%$ \\
Strategy-5: Growth rate (\%) & $26.8 \%$ & $-0.88 \%$ & $50 \%$ & $7.77 \%$ \\
Strategy-1: Interdiction rate (\%) & $0.0 \%$ & $0.0 \%$ & $0.0 \%$ & $0.0 \%$ \\
Strategy-2: Interdiction rate (\%) & $63 \%$ & $63 \%$ & $39 \%$ & $63 \%$ \\
Strategy-3: Interdiction rate (\%) & $40.7 \%$ & $10.6 \%$ & $46.3 \%$ & $27.5 \%$ \\
Strategy-4: Interdiction rate (\%) & $34.4 \%$ & $56.5 \%$ & $53.5 \%$ & $46.5 \%$ \\
Strategy-5: Interdiction rate (\%) & $63.5 \%$ & $63 \%$ & $63.2 \%$ & $63.9 \%$ \\
\hline
\end{tabular}

The figure 8(a) below shows that strategy-2 and strategy-5 yield the lowest leadership growth rate of $27 \%$ operatives respectively; representing the highest annual interdiction rate of $63 \%$ and $64 \%$ respectively. In figure-8(b) above, also shows that strategy-2 and strategy-5 yield the lowest foot-soldiers' growth rate of $-1 \%$ respectively; representing the highest interdiction rate of $63 \%$ respectively, annually. Similarly, in figure-8(c) below, strategy-5 yield the lowest recruiters' growth rate of 50\%, representing an annual interdiction rate of $63 \%$ annually. The figure $8(\mathrm{~d})$, below shows that the overall terrorists' strength in strategy-5 and strategy-2 experienced the lowest growth rates of $8 \%$ and $9 \%$ respectively; representing an annual interdiction rate of $64 \%$ and $63 \%$ respectively.

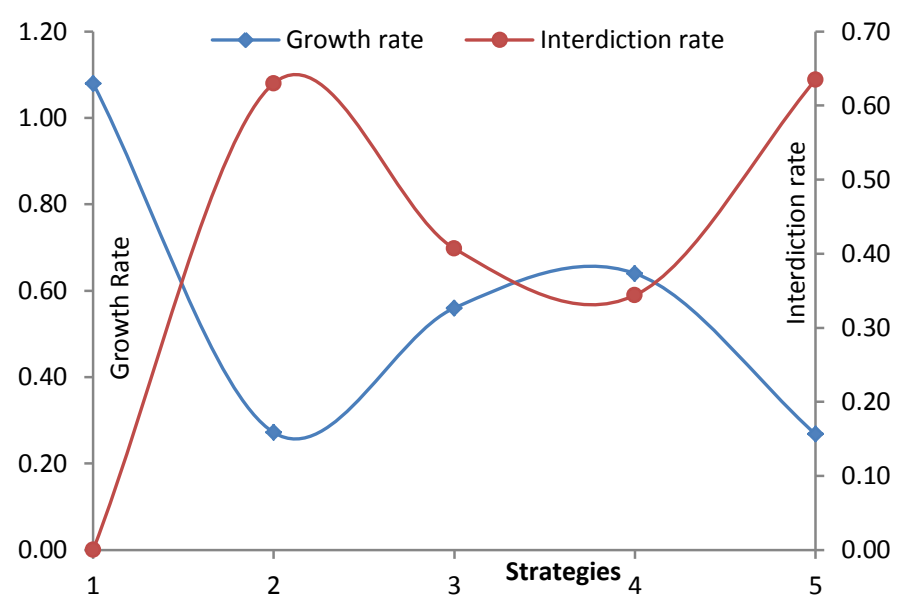

Figure 8(a): Variability of Leaders 'growth with strategy

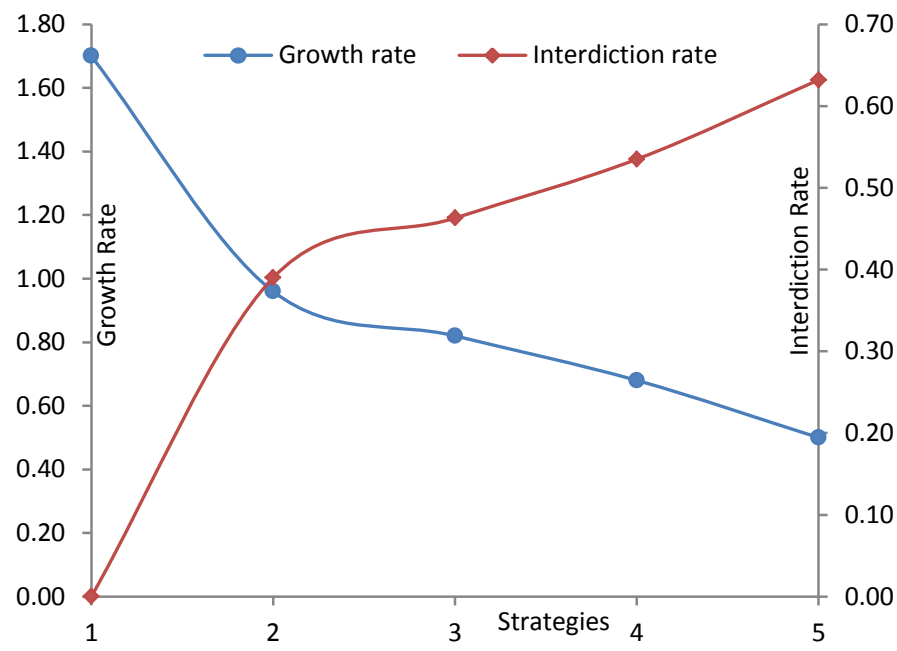

Figure 8(c): Variability of Recruiters growth with strategy

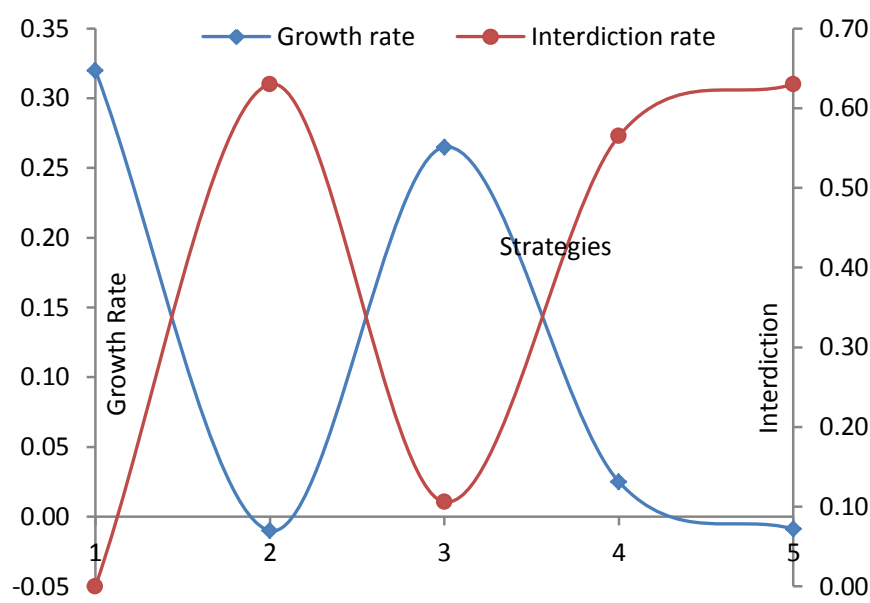

Figure 8(b): Variability of Foot-soldiers 'growth with strategy

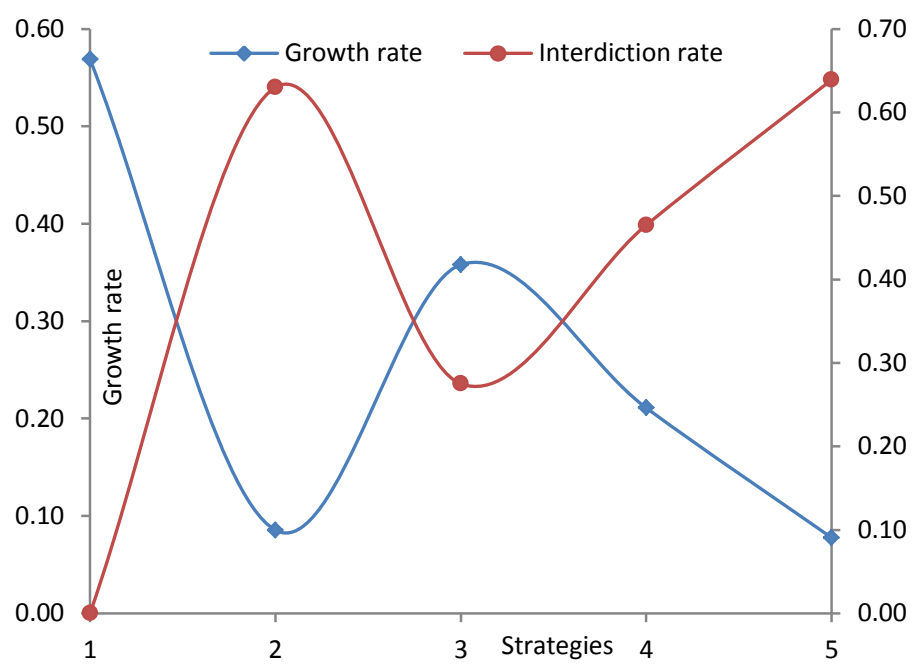

Figure 8(d): Variability of Terrorist strength with strategy 
Numerically, the strength of the terrorist organization under consideration seems to be driven by the dynamics of the foot-soldiers. In strategy-5, a comparatively lowest terrorist strength (238.8) is obtained only at a comparatively highest foot-soldiers interdiction rate (63\%). Similarly, in Strategy-2, a comparatively lower terrorist strength (245.5) is also obtained at a comparatively higher foot-soldiers' interdiction rate (63\%). While in strategy-1, the highest terrorist strength is obtained at the highest foot-soldiers population (see figure 2). And a comparatively higher terrorist strength is also obtained at a comparatively higher foot-soldiers' population (see figure 4). Therefore, we can deduce that, the terrorist organization under consideration is an r-type organization[21].

\subsubsection{Organizational Resilience}

To predict whether the understudied counterterrorism strategies or approaches would be sufficient to degrade or drive the organization to a long term in activity, suffice us to analyze the organization's resilience index of each of the strategy. The "organizational resilience" or the capability of a terrorist group to rebound back and still engage in viable terrorist activity notwithstanding the high degree of decapitation of its operatives is a striking characteristic of most terrorist organization. It is the organization's recovery potential after destruction, which emphasizes the ability of recover and develops in a state of uncertainty, discontinuity, and emergency rather than a resistance to unexpected event. Lengnick-Hall et al[46] defined organizational resilience as a firm's ability to effectively absorb, develop situation-specific responses to, and ultimately engage in transformative activities to capitalize on disruptive surprises that potentially threaten organization survival. The terrorist organizational resilience index is scaled using a minimum-maximum rescaling method:

$$
\operatorname{nomalized}\left(X_{i}\right)=\left|\frac{x_{i}-X_{\min }}{X_{\max }-X_{\min }}\right|
$$

Where $X_{i},(i=1,2,3)$ denote the individual values of strength at each strategy, $X_{\min }$ and $X_{\max }$ denote the minimum and maximum values of $X$ in each strategy, or values representing 3 standard deviations below and above the mean respectively, whichever value is larger. The min-max rescaling method adapted from the University of Notre Dame Global Adaptation Index, compare values for resilience and vulnerability, and then place the terrorist in one of four quadrants, illustrated in Figure 5, below. Using the data on table 2 on equation 5 above, the organization's resilience indices are, Strategy-1, $X_{1}=1.0$ (highly resilience); Strategy-2, $X_{2}=0.15$, (highly vulnerable); Strategy-3, $X_{3}=0.63$, (high resilience); Strategy-4, $X_{4}=0.37$, (lowly resilience); and Strategy-5, $X_{5}=0.14$, (high vulnerable). This implies that, under Strategy-1, the organization $100 \%$ capable of rebounding back to active terrorist activities after significant drain in its overall strength. While the organization's probability of rebounding back to active terrorist activities are $15 \%, 63 \%, 37 \%$ and $14 \%$ under strategy-2, strategy-3, strategy-4 and strategy-5 respectively.

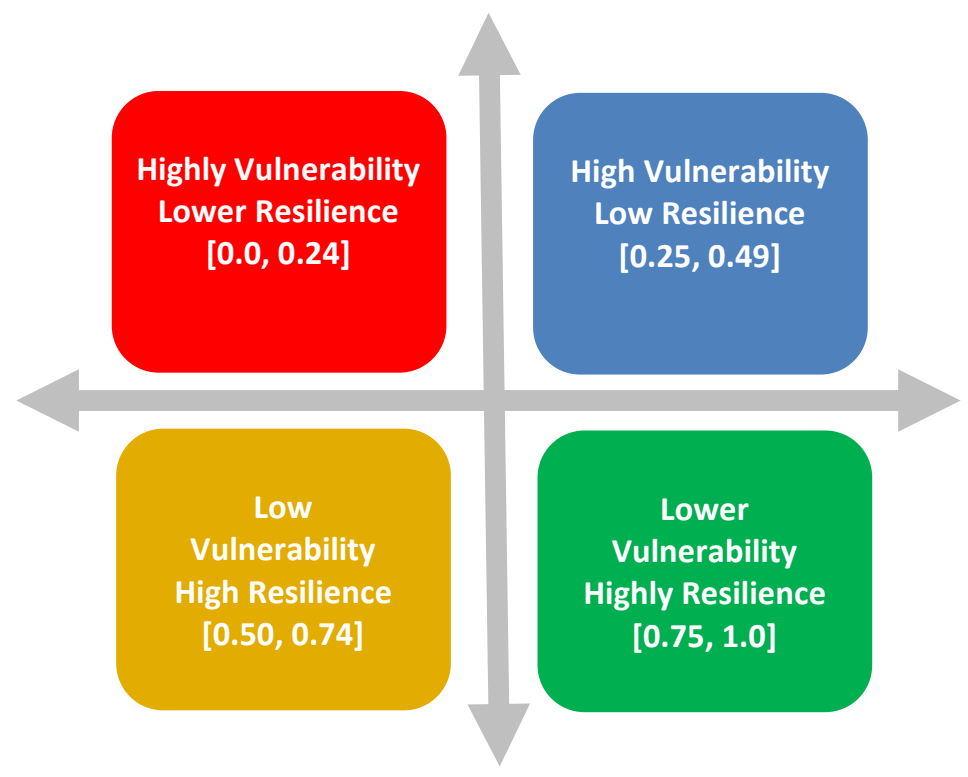

Figure 5: Resilience and Vulnerability Quadrants

\subsection{RESULT OF THE ANALYSIS}

Characteristically, the study shows that the strength of the terrorists' group under consideration, like most terrorist organization is driven by the dynamics of the foot-soldiers. Comparatively, the strategies that yield the highest terrorist interdiction rate (lowest strength) also yield the highest foot-soldiers interdiction rate. While the strategies that yield the highest terrorist strength (lowest interdiction rate) also yield the highest foot-soldiers population. Similarly, the strategy with the highest system interdiction rates also yield the lowest foot-soldiers' growth rates. Thus, the terrorist organization under consideration can be classified as an $r$-type 
organization (i.e. recruitment driven). Therefore, the strategy that guaranteed highest foot-soldiers' interdiction rate, would eventually guarantee a highest system interdiction rate and as well as lowest growth rates of the leadership and recruiters' population respectively; and hence weaken the overall organization's strength. Such strategy would yield a comparatively more effective and efficient CT measures than otherwise. Thus, strategy-2 corresponding to interdicting the foot-soldiers and leadership class simultaneously and strategy-5 corresponding to interdiction targeted at the three classes of terrorist operatives (leadership, foot-soldiers and recruiters) simultaneously would yield an effective and efficient CT strategy. By cost implication, strategy-2, would be more cost effective than strategy-5. However, by definition 3.0 - condition of extinction, the strategy-2 and strategy-5 though yield a highly vulnerable organization with the lowest overall strength, may not be sufficient to guarantee the total collapse of the organization even in the distance future; given the characteristic nature of the exponential growth curves under these strategies. However, according to research findings, an $r$-type organization would be defeated or rendered dysfunctional if it is possible to have a simultaneously constant decline in the leadership $Y(t)$ and foot-soldiers, $X(t)$ population ${ }^{[21]}$.

\subsection{Interdiction targeted simultaneously at the Leaders and Foot-soldier Classes}

This strategy yields an organization of a comparatively low resilience factor, low terrorist growth rate, and very low overall terrorist strength (high interdiction rate), but very high recruiters' growth rate in the period under study. Though the strategy guarantee a very slow growing and vulnerable organization, it may not drive the organization into a long term inactivity (defeated), given the characteristics nature of the exponential growth curves under this strategy (see figure 7b). Intuitively, in most political and ethno-religious ideology driven terrorism, targeting the foot-soldiers class, though required relatively fewer resources than the leadership class, is highly genocidal and contemptuous. Most leaders, by their status in the society, their wealth of experience and financial sovereignty are relatively formidable and volatile to access for proper targeting by relevant CT measures. Most often, effort to target terrorist leaders by relevant CT operatives may result in blowback action by the susceptible youth population, most of whom ignorantly sees these classes of leaders as their political or traditional or religious leaders. Hence, attempt on them is not only provocative and a threat but also an attempt on the collective aspiration and survival of the community. However, given the cost implications and its inherent high vulnerability index, this strategy may yield a more effective result than otherwise. Though the observed long-term evolution of the terrorist strength under this strategy suggests that the probability of the organization going into extinction (defeated) is low (see figure 7a).

\subsection{Interdiction targeted simultaneously at the Leaders and Recruiters Classes}

This strategy yield the lowest overall terrorist interdiction rate, a higher terrorist strength and the highest foot-soldiers' growth rate in the period under study. Ordinarily, this strategy would be preferential, given the weight and premium placed on the role of these classes of operatives in any terrorist organization. However, given the political and ethno-religious ideology drivers of most terrorist organizations, any attack on these two classes of operatives; most of whom are religious or traditional or political leaders, usually create disaffection, rancor, disharmony and tension among the local population (the source of new insurgents); since most of them are seen as representing and pursuing the collective aspiration and interest of the community. This help to fuel and heighten animosity and as well as fanning the amber of enmity between the government and the locals. Thus, often times causing blowback actions often experienced after every major CT operation. Blowback actions could provoke "Herostratos syndrome" among the youth population, which help to pump-up more support and recruitment to the terrorist organization[4,6,52]. Therefore, CT measures targeted at terrorists' leaders and recruiters termed decapitation strategy is prone to evolving a highly resilience organization (see section 3.5.2).

\subsection{Interdiction targeted simultaneously at the Foot-soldiers and Recruiters Classes}

This strategy yields the second highest overall terrorist interdiction rate and the third highest terrorist strength in the period under study. Ideally, this seems to be the most conventional CT approach employed by most security agencies in recent time. Since most terrorist leadership seems to be very formidable, untouchable and inaccessible to most CT measures, beside the high propensity of inciting blowback effect from their subjects (local population). As observed in section 3.3.3, terrorist recruiters are special class of terrorist whose catalytic role and salient responsibilities to the organization renders them highly security conscious and difficult if not impossible to target properly by most CT operatives. Most often recruiters operate clandestinely, hence their relatively unperturbed high growth rates under the conventional CT measures. However, a proactive effort at targeting these two classes of operatives promises to evolve a low resilience (high vulnerability) organization; as the recruiters' class is both the gateway and factory for the production and transformation of the potential recruits into radical foot-soldiers.

\subsection{Interdiction targeted simultaneously at the Leaders, Foot-soldiers and Recruiters Classes}

Strategically, this strategy yields the highest interdiction rates of leaders, foot-soldiers, and recruiters respectively, and as well as the lowest overall terrorist strength, within the period under study (5 years). By organizational resilience, a proactive effort toward 
attacking these three classes of operatives simultaneously, promises to yield a highly vulnerable organization. However, though, this strategy seems most effective CT measure than other strategies, resource wise, it is cost intensive, very challenging, contemptuous and genocidal given the caliber of operatives. Hence, observation of the long-term evolution of the terrorist strength under this strategy suggests that the probability of the organization going into extinction (defeated) is low, given the characteristics nature of its exponential growth curves (figure $7 \mathrm{a}$ ).

\subsection{Condition for Optimality and Demise of the Organization}

Though terror war of attrition is problematic and highly cost intensive, however, increasing interdiction accuracy is the best-case scenario for ideal CT measures[37]. As a recruitment driven organization, any strategy that simultaneously hinders the entrance of potential recruits and as well maintained constant high interdiction rate of the foot-soldiers and the leadership classes, would eventually guarantee lowest growth rate and highly vulnerable organization. This would result in the lowest growth rates of the recruiters' class, and hence weakening of the overall organization's strength. Psychologically, this postulation agreed with intuition, because recruitment generate the more numerous foot-soldiers needed to carry out attacks and sustained operations; experienced combatant foot-soldiers generate skilled leaders, experienced managers, weapon experts, and other key decision making echelon of the organization; and few skillful and experienced leaders in turn are often commissioned for recruiters' privileges[48].

Therefore, to allocate CT resources optimally, the priority of CT campaign must go beyond responding to terrorist attacks and threats, to taking proactive steps toward crippling not only the existing pool of terrorist foot-soldiers and leaders but most importantly the recruiters and their recruitment institutions. Since manpower for carrying out attacks and sustaining operations is a critical resource for terrorist organizations; therefore, hindering recruitment processes strikes an indelible blow on terrorist ability to function. The key prong of this proactive strategy is to diminish both the ability and the environment susceptible for the terrorist organizations to recruit new members. This can be achieved through the following measures:

4.5.1 CT Measures Targeted at the Terrorist Recruitment Processes: The first step toward hindering terrorist recruitment process is to understand how the process works - where terrorist organization recruits, what tools it uses, whom it targets, and why. These may not be limited to the structure of the recruitment process; the models terrorist organization are using to attract new members; recruitment approaches; characteristics of potential recruits; and nodes - centers of activity such as mosques; social media; educational institutions; socio-cultural organizations; NGOs and charity organizations - where terrorists' recruiters seek new members and where potential recruits are likely to become acquainted with the radical jihadist worldview ${ }^{[48]}$. A clearer picture of terrorist recruitment process could help the security organization and its stakeholders develop strategies not only to integrate holistic CT measure but also interventions to counter terrorist groups' ability to replenish and increase their numbers. Therefore, in view of the viability of the indispensable hidden catalytic role of terrorist recruiters, this study recommend the proper identification and inclusion of recruiters class, and as well as their recruitment institutions as a pragmatic target for ideal CT operations. Conscious effort to targeting terrorist recruiters and their recruitment institutions along with the leaders and footsoldiers simultaneously is one of the necessary conditions for optimal CT strategy.

4.5.2 Sufficient and Credible Intelligence Gathering for Proper Targeting of Terrorist: To guarantee optimal interdiction (killing accuracy) of terrorist operatives, sufficient and credible intelligence gathering system is a panacea. Research finding over the last centuries, indicate that warfare against terror has been constraint by the heterogeneity of the terrain; the asymmetric nature of the warfare; the insufficient and unreliable information and as well as limited human and material resources at the disposal of security agencies and CT decision makers. These has often accounted for the collateral damage (large casualties) and mass killing when large-scale military operations take a high-force buck-shot approach toward eradicating terrorists' cells within a locality. Oftentimes such mass killing which involve innocent civilians' population has been one of the major drivers of disaffection, disharmony and tension that help fueled and heighten animosity throughout the civilian population (the source of new insurgents) and as well as fanning the amber of enmity against the government. Thus, causing the blowback actions often experienced after every major CT operation[53]. Blowback actions provoke "Herostratos syndrome" among the youth population; which help to pump-up more support and funding for the radical terrorist group and in addition, cause more recruitment to the terrorist organization[4,6,53] - a process which is counter-productive to government's policy justification for such CT measures. Herostratos syndrome is a destructive youth heroism, named after a Greek youth who sought immortality via destruction[5,6,20]. Usually recruited in groups of friends, members socially reinforce each other's Herostratos syndrome, justifying destructive crimes within new group norms[4,6].

Therefore, to avert such boomerang consequence, the present study recommends the infiltration of terrorist organization with highly motivated, proactive, and dynamic network of "deep" undercover human intelligence "agents" or "informants" who would function as integral part of the organization; to provide credible and sufficient intelligence (secret information) about a target 
under investigation. This would reverse the reinforcing loop by both increasing the number of terrorist drain and defectors and as well as enhancing sufficient and credible intelligence gathering for smart-targeting. Increased numbers of terrorist defectors would complement accurate intelligence for smart-targeting of insurgent locations and as well as engendered high internal terrorist defections. Civilian deaths would be reduced if the killings were more selective.

According to US Directorate of Defense doctrine 1998: "Targeting is the process of selecting targets and matching the appropriate response to them, including operational requirements and capabilities". The purpose of targeting is to disrupt, delay, or limit threat interference with friendly[51] course of action (COAs). Human-targeting, the process of selecting a human target exists as a subset of the more general targeting doctrine as applied to terrorists. Human-targeting is intent or objective neutral. Though human targeting does not specify the type of action to be taken or the CT objective desired, however, it represents an analytical process that assigns a heuristic value to a target. This assignment of value allows for the prioritization of multiple targets and thus permits CT organizations to direct efforts and allocate the required resources. Consequently, every government agency, unit, or official whose function serves to counter terrorism remains dependent on the human-targeting process[44]. Thus, increasing killing accuracy is the best-case scenario for any military CT measure. Furthermore, under the influence of the "deep" secret agents, detected plots rarely manage to execute successful attacks both because the terror interdiction agents are so versatile that detection usually leads to capturing fairly quickly and because the "deep" undercover agents will literally "take control" of the plots - by infiltrating and becoming part of the plots. Thus, we assume that successful terror attacks may only result from unknown terror plots, which may not be possible except from unknown or newly formed terrorist organization.

\subsubsection{De-legitimization of Terrorism and Terrorist Ideology from the Local Population: Given the high correlation} between ideological strength and insurgent community size, and given most insurgents' employment of ideology as a currency to recruit supporters; the size of the insurgent community may serve as a proximal metric of its ideological strength. Psychologically, every religious and ethno-ideologically driven terrorism are derivatives of a specific part of the population and are perceived to fighting for the cause and rights of their group, hence terrorist oftentimes find great support within their home population and their cause are oftentimes seen as a legitimate one by the home population[29,39],. Moreover, ethno-ideologically driven terrorism has common underlying issues that cause the violence to escalate and because ethno-ideological groups are oftentimes closely intermingled and connected to the population they represent, "they seek and promote this identity through terrorist activities, which $(i)$ creates communal bonds that result from the retaliation of the government or rival communities, and (ii) the inevitable persecution that follows draws attention to their cause among the larger population, thus, increasing their numbers and financial support' $[8,14,16,42]$,.

Furthermore, since terrorists do not wear identifying military uniforms, are not confine to designated geographical hubs (e.g. barracks) nor do they obey the conventional military warfare rules and regulations, therefore, an ideal CT measures must include a commitment to psychologically de-legitimize terrorism and its propaganda among local population. Taking the local populations support away from the terrorist's organization will creates serious havoc for the terrorists and its cause receives less attention and therefore becomes delegitimized. For an ideal de-legitimization process, government must give the local population more legitimacy and concession in order to gain their cooperation and supports. The security agencies must promote, encourage and protect the privacy of local population who can serve as the necessary informants. They must cooperate and work together with the moderate local population, motivate and respect their fundamental human right and liberty. These will engender trust and confidence building between the governed and the government; garner the necessary moral supports for the initiation of an allinclusive, proactive and efficient "in-group policing" mechanism between the security agencies and the local population; and encourage and facilitate sufficient and credible intelligence gathering[28,42,43]. These efforts are not only the necessary and sufficient conditions for ideal CT measures but imperative because every ethno-ideological driven terrorism are derivatives of a specific part of the population and are perceived to fighting for the cause and rights of their group.

\subsubsection{Encouraging or Enhancing Internal Personnel' Defection}

Fatigue and attrition of personnel have been empirically found to impact negatively on the dynamical evolution of terrorist organizations. In interviews with captured or retired terrorists, reveals that they often complained about the psychological stress of their past work, its moral contradictions, and the isolation from relatives and friends[26]. This is part of the reason why terrorist organizations cannot remain inactive (as in a cease fire) for very long time without experiencing irreplaceable loss of personnel due to loss of motivation, and many organizations even resort to coercion against desertion. Therefore implementing measures that encourage operatives to defect voluntarily through a viable "carrots and sticks" approach - advocacy or amnesty programs or "Delilah's syndrome" would impact positively on the effectiveness of any CT measures. The present model brings theoretical insight into such phenomenon. One prediction of the model is that even if such operative defection exceeds recruitment $(i . e . d>$ $r$ ) the organization would still sustain itself as long as it has a sufficiently large rate of commissioned (c) recruiters, or promotion 
$(p)$ of leaders of sufficiently high caliber $(m)$. However, if desertion is much greater, say $(d \gg r)$, then the model predicts that with minimal interdiction, the organization would be destroyed regardless of starting conditions, or the strength of CT efforts.

4.5.5 Mass Literacy, Compulsory Qualitative Education and Increase Employment Opportunity: Major index of terrorism prevention is education and unemployment. As much as education is the key to any nation's socio-economic development objectives, it is also the key to ethno-ideological crimes like terrorism. According to UNICEF, Amnesty International[2,3] and Human Right Watch[28], high illiteracy and unemployment rates are major driving forces behind most ethno-ideologically driven terrorism, especially in Africa. Illiterate youths below the age of 18 form about $45 \%$, while unemployed youths account for about $64 \%$ of the entire population of most terrorist organization such Boko Haram, ISIS, AQIM, AlQaeda, Al-Shabab, etc. This underlying issue has advanced the establishment of most Islamic schools with Islamic fundamentalist curricula in their related countries. This provide only but obsolete learning environment than the state funded modern schools. These schools hitherto turned out to be the main recruitment opportunity for ethno-religious ideology driven terrorist organizations[28,50]. Therefore, government's socio-economic reforms and developmental objectives that emphasizes compulsory mass literacy and qualitative education, and as well as create sustainable employment opportunities for the teaming and vulnerable unemployed youth population is a panacea to effective terrorism prevention.

\section{CONCLUSION}

In the study, a differential equation model of a terrorist organizational dynamics is developed and analyzed; to study the possible strategy for allocation the available human resources toward an optimal CT operation. Although operational, organizational, and political circumstances may vary widely across terrorist groups, the simple generic nature of our results suggests several general conclusions which are not only in affirmative with intuition but also lead to empirically probable evidence. First, the efficacy of the dynamics of the foot-soldiers driving the evolutional dynamics of most terrorist organization is highlighted and empirically appraised. Secondly, the viability of the often undermined hidden catalytic role of terrorist recruiters class that help to speed up the recruitment and transformation process, thereby allowing a terrorist organization to grow through a sustained support-base that is constantly supplying new personnel for the possible conversion into radical foot-soldiers, notwithstanding any orchestrated CT measures has also been brought to limelight and empirically assessed. Thirdly, the inherent potential of mathematical methods and differential equation in particular, to create impact in a variety of targets, including complex and divergent socio-economics problems like terrorism, is also demonstrated. The model which does not only serve as a quantitative metrics to measure the degree of success or otherwise of a given CT measures but also help to evaluate the impact of the various CT strategies on the structural dynamics of a given terrorist organization; hence predicting the evolution of terrorist conflicts and as well as its possible solution.

Empirically, the study reveals that, given that the recruitment process is a major driver of most terrorist evolutional dynamics, any strategy that is capable of maintaining a constant high interdiction rate of the foot-soldiers and the leaders, would eventually guarantee a maximum decline in the overall strength of the organization, and as well as engenders a maximum decline in the recruiters' population. Such strategy has the potential to weaken the overall terrorists' strength and thus, drive the organization to its demise in the long runs. For our model organization, targeting the leaders, foot-soldiers and recruiters simultaneously yield a comparatively more effective and efficient CT measures than otherwise. However, given the cost implications of sustaining such interdiction strategy, the formidability of most religious and ethno-ideologically driven terrorism leadership, and as well as the clandestine nature of most terrorist recruitment activities, targeting the leaders and foot-soldiers simultaneously would yield a comparatively more cost effective CT measure.

The study's result also collaborates proponent of terror war of attrition: "that though terror war of attrition is problematic and cost oriented, however, increasing killing (interdiction) accuracy is the best-case scenario for any military offensive CT measure "[37]. But however recommended that, to guarantee such killing accuracy, sufficient and credible intelligence for smarttargeting of insurgent locations is a panacea. Hence, to guarantee sufficient and credible intelligence gathering, the study recommends that government must be committed to the process of de-legitimization of terrorism and terrorist ideology from the local population by (i) giving the local population more legitimacy and concession, promote, encourage and protect their privacy in order to gain their cooperation and supports; (ii) Security agencies must cooperate and work together with the moderate local population, motivate and respect their fundamental human right and liberty. These will engender trust and confidence building between the locals and the government; garner the necessary moral supports for the initiation of an all-inclusive, proactive and efficient "in-group policing" mechanism between the security agencies and the local population; and facilitate and encourage efficient intelligence gathering for smart-targeting, selective and killing accuracy[28,21,43]. It is on the judicious implementation of these recommendations that the study hang the hope and aspiration of the relevant democratic governments to create an enduring long-term negative impact on the future prospect of terrorism and as well as other epidemic of insurrectionary activities in human society.

www.ijasre.net

Page 113 


\section{REFERENCE}

[1.] Aaron C. and Kristian S. G., (2011): The Developmental Dynamics of Terrorist Organizations. Santa Fe Institute, Santa Fe, NM 87501, USA and Centre for the Study of Civil War, Oslo, Norway.

[2.] Amnesty International, (2012): "Nigeria: Trapped in the Circle of Violence', 47.

[3.] Amnesty International, (2013): Document-Nigeria: Authorities must investigate deaths of Boko Haram suspects in military custody. https://www.amnesty.org/en/library/asset/AFR44/en.html.

[4.] Bandura, A. (2004): The role of selective moral disengagement. In F. M. M. Moghaddam, E. J. (Eds.), Understanding terrorism: Psychological roots, consequences, and interventions. Washington, DC: American Psychological Assn.

[5.] Borowitz, A. (2005). Terrorism for self-glorification: The Herostratos syndrome.

London: Kent State University Press.

[6.] Burke, J. (2003): Al-Qaeda: Casting a shadow of terror. New York: I. B. Tauris.

[7.] Butler, L.B. (2011): Hezbollah: The Dynamics of Recruitment. US Marine Corps, School of Advanced Military Studies. US Army Command and General Staff College, Fort Leavenworth, Kansas AY 2011-01.

[8.] Byman, D.L. (Spring 1998): The logic of Ethnic Terrorism. Studies in Conflict and Terrorism, Vol. 21, pp. 149-169.

[9.] Castillo-Chavez, C., and Song, B., (2003): Models for the transmission dynamics of fanatical behaviors. In Bioterrorism: Mathematical Modeling Applications in Homeland Security, SIAM, Philadelphia, 155-172, 2003.

[10.] Caulkins, J.P., Grass, D., Feichtinger, G., and Tagler, G., (2008): Optimizing counter-terror operations: Should one "fight fire with fire" or "water"? Computers \& Operations Research 35, 1874-1885, 2008.

[11.] Chamberlain, T. (2007): "Systems Dynamics Model of Al-Qaeda and United States Competition", J. Homeland Security and Emergency Management, vol. 4, no. 3:14, pp. 1-23, 2007.

[12.] Clauset, A., Young, M., and Gleditsch, K. S., (2007): On the frequency of severe terrorist events. Journal of Conflict Resolution 51 (1), 58-87.

[13.] Country Reports on Terrorism (CRT) 2015: United States Department of State Publication Bureau of Counterterrorism and Countering Violent Extremism Released June 2, 2016.

[14.] Daxecker, Ursula E. and Michael L. Hess. (2013): "Repression Hurts: Coercive Government Responses and the Demise of Terrorist Campaigns”. British Journal of Political Science 43 (3): 559-577.

[15.] Douglas D. Mooney and Randall J. Swift, (1999): A Course in Mathematical Modeling (The Mathematical Association of America, 1999), 314.

[16.] Dugan, Laura and Erica Chenoweth. (2012): "Moving Beyond Deterrence: The Effectiveness of Raising the Expected Utility of Abstaining from Terrorism in Israel”. American Sociological Review 77 (4): 597624.

[17.] Farley, J.D. (2007): "Evolutionary Dynamics of the Insurgency in Iraq - A Mathematical Model of the Battle for Hearts and Minds," Studies in Conflict and Terrorism 30 (2007).

[18.] Farley, J.D. (2007) Toward a Mathematical Theory of Counterterrorism: Building the Perfect Terrorist Cell. California Institute of Technology; The Proteus Monograph Series, Vol 1, Issue 2. December 2007.

[19.] From a leaked 2003 memo (USA Today, October 22, 2003).

[20.] Greenberg, K. (Ed.). (2005): Al Qaeda now: Understanding today's terrorists. New York: Cambridge University Press.

[21.] Gutfraind, A. (2009): Mathematical Terrorism: "Understanding Terrorist Organizations with a Dynamic Model." Studies in Conflict \& Terrorism 32: 45-59, SIAM Journal, October 2009.

[22.] Guiora, A. N., (2007): Global Perspectives on Counterterrorism. Aspen Publishers, New York.

[23.] Guiora, A. N., (2008): Fundamentals of Counterterrorism. Aspen Publishers, New York.

[24.] Harmon, C. C. (2000): Terrorism Today. Oxford, UK: Routledge, $1^{\text {st }}$ Ed., 2000.

[25.] Hoffman, B. (2004): “Al-Qaeda; Trends in Terrorism and Future Potentialities" - An assessment Studies in Conflict and Terrorism, vol. 26, pp. 429-442, Nov-Dec 2003.

[26.] Horgan, J. (2005): The Psychology of Terrorism. New York, NY: Routledge, Sep 2005.

[27.] Heymann, P., (2003): Dealing with Terrorism after September 11, 2001: An Overview. In Countering Terrorism: Dimensions of Preparedness, MIT Press, 57-72, 2003.

[28.] Human Rights Watch, (2014): "Illusion of Justice: Human Rights Abuses in US Terrorism Prosecutions". July 2014;

[29.] Indridason, Indridi H. (2008): "Does terrorism influence domestic politics? Coalition formation and terrorist incidents". Journal of Peace Research 45 (2): 241-259.

[30.] Johnson, N. F., Spagat, M., Restrepo, J. A., Becerra, O., Bohorquez, J. C., Suarez, N., Restrepo, E. M., and Zarama, R., (2006): Universal patterns underlying ongoing wars and terrorism. Preprint. http://arxiv.org/physics/0605035 (accessed on May 3, 2006). 
[31.] John H. Miller and Scott E.P., (2007): Complex Adaptive Systems: An Introduction to Computational Models of Social Life (Princeton, NJ: Princeton University Press, 2007), 165-166.

[32.] Joint Publications 3-26, Counterterrorism, 13 November 2009, US Army, US Navy, US Joint Chief of Staff, US Air Force, US Marine Corps and US Coast Guard. Joint Doctrine Analysis Division, 116 Lake View Parkway, Suffolk, VA 23435-2697.

[33.] Jongman, A. J. and Schmid, A. P. (2005): Political Terrorism. Piscataway, NJ. Transaction Publishers, 2005.

[34.] Kaplan, E.H., Mintz, A., Mishal, S., and Samban, C., (2005): What happened to Suicide Bombings in Israel? Insights from a Terror Stock Model. Studies in Conflict and Terrorism 28, 225-235, 2005.

[35.] Kaplan, E. H., \& Kress, M., (2005): Operational effectiveness of suicide bomber-detector schemes: A best-case analysis. Proc. Natl. Acad. Sci. 102 10399-10404.

[36.] Keohane, N. O. and Zeckhauser, R. J., (2003): The ecology of terror defense. Journal of Risk and Uncertainty, 26(23):201-29.

[37.] Kress, M., \& Szechtman, R. (2009): Why defeating insurgencies is hard: The effect of intelligence in counterinsurgency operations - A best case scenario. Operations Research 57(3), 578-585.

[38.] Lanchester, F.W. (1916): Aircraft in Warfare - The Dawn of the fourth arm - principal of concentration, Engineering, 1916. Vol. 98, pp.422-423.

[39.] Langlois, Catherine C. and Jean-Pierre Langlois. (2011): “The Escalation of Terror: Hate and the Demise of Terrorist Organizations". Conflict Management and Peace Science28 (5): 497-521.

[40.] Lengnick-Hall, C. A., Beck, T. E., \& Lengnick-Hall, M. L. (2011): Developing a capacity for organizational resilience through strategic human resource management. Human Resource Management Review, 21(3), 43-255.

[41.] Leskovec, J., Krause, A., Guestrin, C., Faloutsos, C., Van Briesen, J., and Glance, N. (2007): “Cost-effective outbreak detection in networks," in KDD '07: Proceedings of the 13th ACM SIGKDD international conference on Knowledge discovery and data mining, (New York, NY, USA), pp. 420-429, ACM, 2007.

[42.] Maike Knoechelmann (2014): Why the Nigerian Counter-Terrorism policy toward Boko Haram has failed - A cause and effect relationship. International Institute for Counter-Terrorism (ICT), ICTWPS October 2014.

[43.] Okorie Hagler. (2015): “Counter- Insurgency, Rule of Law and the Fight against Boko Haram in Nigeria” July, 31 2015.

[44.] Ormond, B. and Williams, A. (2014): Using Multi-Attribute Decision Making and Comparative Evidence to Improve Counter-Terrorist Decisions. Master's Thesis, NPS, June 2014.

[45.] Richardson, L. F. (1941): Frequency of occurrence of wars and other fatal quarrels. Nature 148, 598.

[46.] Richardson, L. F. (1948): Variation of the frequency of fatal quarrels with magnitude. Journal of the American Statistical Association 43, 523-546.

[47.] Sandler, T., Tschirhart, J. T., and Cauley, J., (1983): “A Theoretical Analysis of Transnational Terrorism,” American Political Science Rev, vol. 77, pp. 36-54, Mar 1983.

[48.] Scott Gerwehr and Sara Daly, (2010): Al-Qaida: Terrorist Selection and Recruitment. The RAND Corporation, www.rand.org/pdfrd/publications/electronics.

[49.] Udwadia, F., Leitmann, G., Lambertini, L., (2006): A Dynamical model of terrorism. Discrete Dynamics in Nature and Society, 1-32, 2006.

[50.] Umar, S.M., (2003): Profiles of New Islamic Schools in Northern Nigeria. The Maghreb Review, Volume 28 (1-2), pp. 146-169.

[51.] U.S. Army DCSINT, (2007): A Military Guide to Terrorism in the Twenty-First Century. Handbook No. 1 (Version $3.0)$.

[52.] Weaver, E. A. (2008): The role of influence operations in a counterinsurgency battle. Journal of Defense Modeling and Simulation 5(1).

[53.] Wolf, J. B. (1989): Anti-Terrorist Initiatives. New York: Plenum Press, 1989. 